\title{
The use of the Molecular Adsorber Coating technology to mitigate vacuum chamber contamination during Pathfinder testing for the James Webb Space Telescope
}

\section{- Nithin S. Abraham}

Presented on Wednesday, August 31st, 2016

SPI E Paper 9952-11

Session 3: Space Mission Contamination: Technology Application, Testing and Flight Measurements

Nithin S. Abraham, Mark M. Hasegawa, Eve M. Wooldridge NASA Goddard Space Flight Center, Greenbelt, Maryland

Kelly A. Henderson-Nelson

Stinger Ghaffarian Technologies, Inc., Greenbelt, Maryland

SPIE Optics + Photonics: Optical Engineering + Applications 


\section{Abstract}

As a coating made of highly porous zeolite materials, the Molecular Adsorber Coating (MAC) was developed to capture outgassed molecular contaminants, such as hydrocarbons and silicones. For spaceflight applications, the adsorptive capabilities of the coating can alleviate onorbit outgassing concerns on or near sensitive surfaces and instruments within the spacecraft. Similarly, this sprayable paint technology has proven to be significantly beneficial for ground based space applications, in particular, for vacuum chamber environments. This paper describes the recent use of the MAC technology during Pathfinder testing of the Optical Ground Support Equipment (OGSE) for the James Webb Space Telescope (JWST) at NASA Johnson Space Center (JSC). The coating was used as a mitigation tool to entrap persistent outgassed contaminants, specifically silicone based diffusion pump oil, from within JSC's cryogenic optical vacuum chamber test facility called Chamber A. This paper summarizes the sample fabrication, installation, laboratory testing, post-test chemical analysis results, and future plans for the MAC technology, which was effectively used to protect the JWST test equipment from vacuum chamber contamination.

- Keywords: Molecular Adsorber Coating, zeolite, molecular adsorber, adsorber, adsorption, outgassing, molecular contamination, spaceflight applications, vacuum applications, James Webb Space Telescope, JWST, Chamber A, DC-704, diffusion pump oil, silicones, sprayable paint technology, coatings, getters, passive getter 


\section{Table of Contents}

\section{- Introduction}

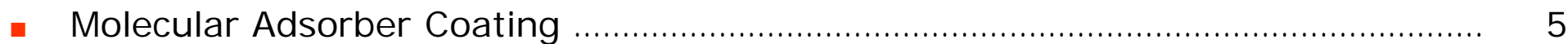

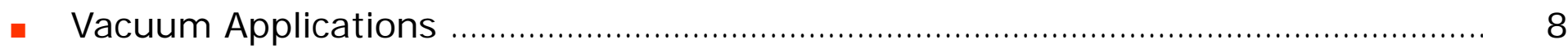

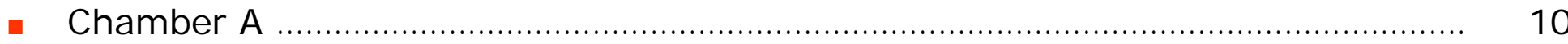

- Molecular Contaminants ....................................................................... 14

- Application Efforts

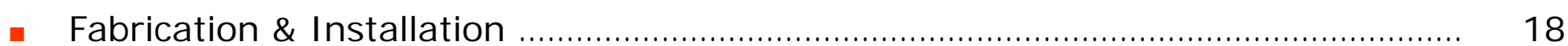

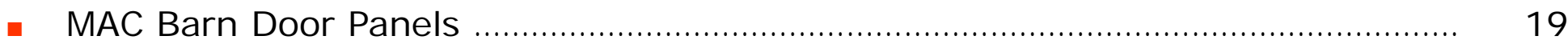

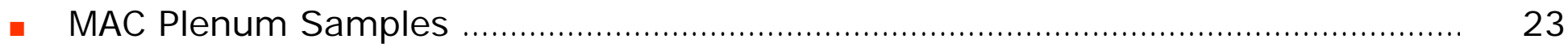

\section{- Testing Efforts}

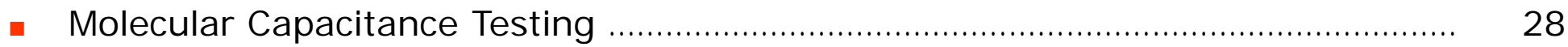

- Chemical Analysis

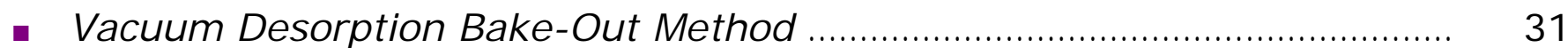

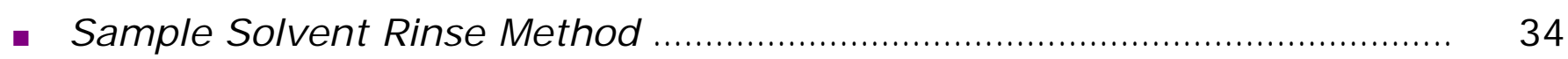

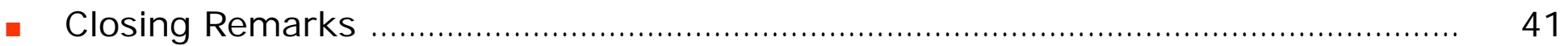

- Conclusions

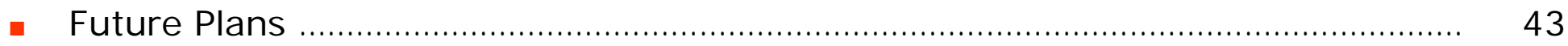

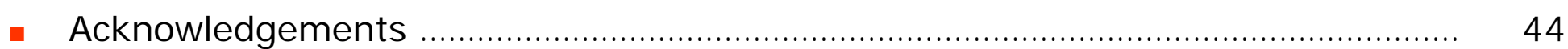

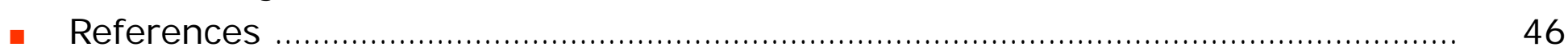

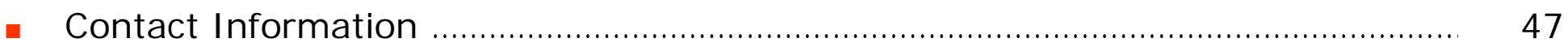




\section{Introduction}

- Molecular Adsorber Coating

- Vacuum Applications

- Chamber A

- Molecular Contaminants 


\section{Molecular Adsorber Coating}

- Developed by NASA Goddard Space Flight Center (GSFC)

- Sprayable, zeolite based and highly porous coating technology that was designed to passively capture outgassed contaminants

- Available in white and black coating variations

- White Molecular Adsorber Coating, GSFC MAC-W

- Black Molecular Adsorber Coating, GSFC MAC-B

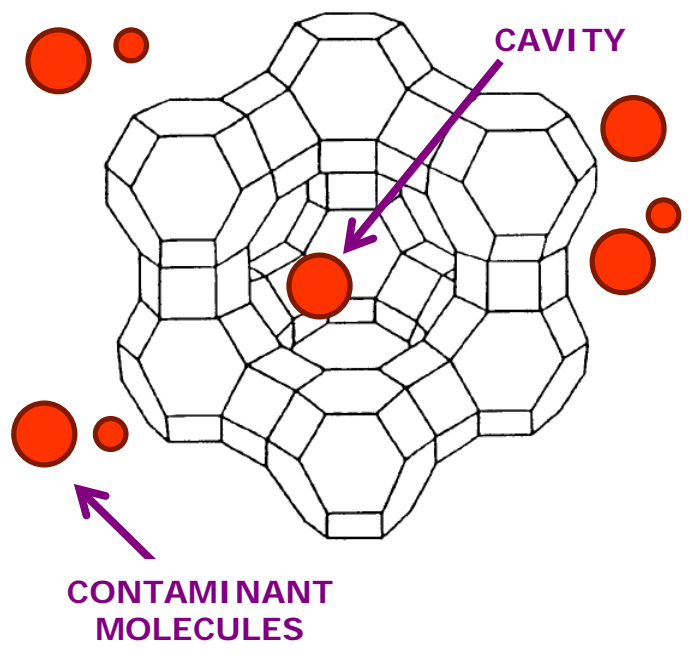

- Examples of molecular contaminants include high molecular weight chemical species, such as:

- Hydrocarbons

- Phthalates

- Palmitates

- Esters

- Silicones
- Sources of contaminants are products of outgassing from materials found within the spacecraft, such as:

- Plastics

- Adhesives

- Lubricants

- Epoxies

- Potting Compounds 


\section{Molecular Adsorber Coating}

- Designed to be used as a contamination control mitigation method to address material outgassing concerns on or near sensitive surfaces and instruments:

- Inside instrument cavities, electronics boxes, detectors, and baffles

- Near components such as, telescopes, cameras, lasers, mirrors, and optics

- Reduces the risk of on-orbit molecular contamination from degrading the performance of spaceflight hardware

- Through GSFC's Internal Research and Development (IRAD) program, significant testing and demonstration efforts were performed in relevant environments (i.e. vacuum) for spaceflight applications

- Adsorptive Capabilities

- Thermal/Optical Properties

- Adhesion Performance

- Thermal Stability

- Particulate Characteristics

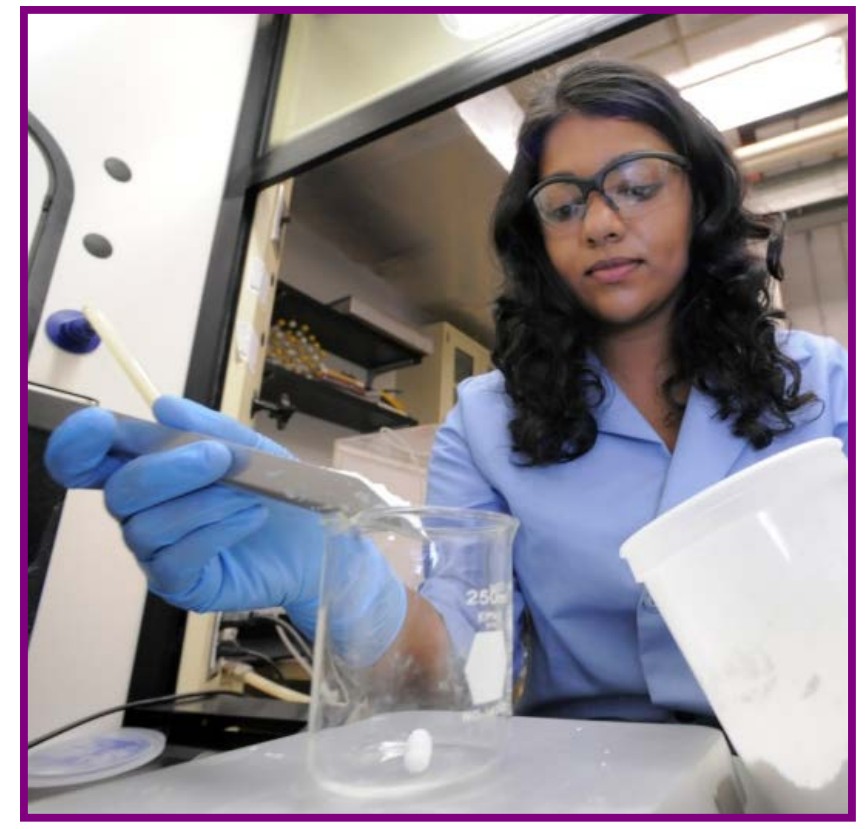

Photo Credit: NASA/Pat Izzo 


\section{Molecular Adsorber Coating}

- MAC provides several advantages as an innovative coating technology

- Serves as a multi-purpose contamination control coating (thermal, straylight)

\begin{tabular}{|c|c|c|c|c|}
\cline { 2 - 5 } \multicolumn{1}{c|}{} & $\begin{array}{c}\text { WHITE } \\
\text { THERMAL } \\
\text { CONTROL } \\
\text { COATI NG }\end{array}$ & $\begin{array}{c}\text { WHITE } \\
\text { MAC }\end{array}$ & $\begin{array}{c}\text { BLACK } \\
\text { MAC }\end{array}$ & $\begin{array}{c}\text { BLACK } \\
\text { THERMAL } \\
\text { CONTROL } \\
\text { COATI NG }\end{array}$ \\
\hline $\begin{array}{c}\text { Molecular } \\
\text { Contamination Control }\end{array}$ & & $\sqrt{ }$ & \\
\hline $\begin{array}{c}\text { Thermal Control } \\
\text { Properties }\end{array}$ & $\boldsymbol{V}$ & $\boldsymbol{V}$ & $\boldsymbol{V}$ \\
\hline $\begin{array}{c}\text { Optical Stray } \\
\text { Light Control }\end{array}$ & & & $\sqrt{ }$ \\
\hline
\end{tabular}

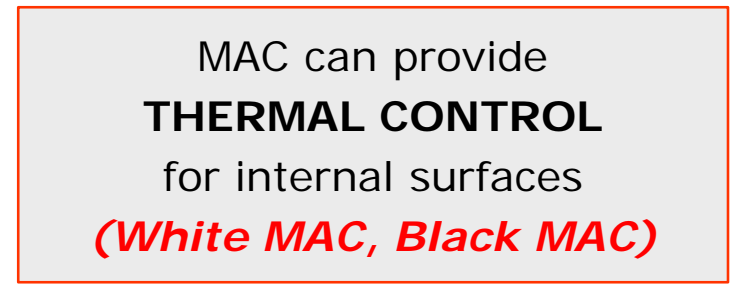

MAC can provide

STRAYLI GHT CONTROL for baffles and optical surfaces (Black MAC)

- Low mass (adds very little additional mass to the spacecraft)

- Cost effective (made from low cost materials)

- Ease of sprayability onto most substrates (with optimal adhesion performance)

- Tailorable adsorption characteristics (thickness dependent)

- Low outgassing properties (made from inorganic materials)

- Limited particulation effects (with cleaning mitigation techniques available) 


\section{Vacuum Applications}

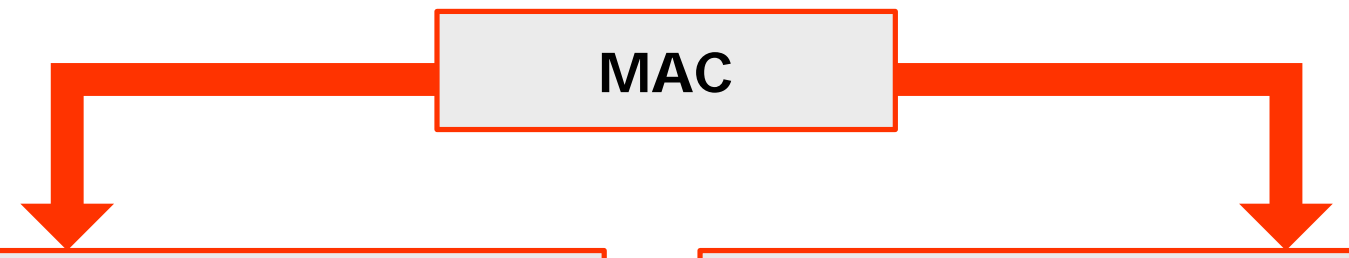

\section{FLI GHT BASED SPACE APPLICATIONS}

MAC was originally designed to mitigate on-orbit molecular contamination for flight based space applications within the spacecraft

\section{GROUND BASED SPACE APPLICATIONS}

MAC has also proven to be significantly advantageous for ground based space applications, in particular, for vacuum chamber environments

\section{Use of MAC in Vacuum Chamber Environments}

- As a passive getter material and as an additional vacuum pump

- In industry, the use of getters is a common practice within vacuum systems, such as chambers or hermetically sealed containers

- Getters are often used to improve and maintain vacuum efficiency by scavenging molecular contaminants from the evacuated space by absorption, adsorption, or chemical binding

- Although there are no mechanical moving elements to the coating, MAC may be described to be analogous to a vacuum pump

- A vacuum pump removes molecules from an enclosed volume 


\section{Vacuum Applications}

- Some advantages of using MAC in vacuum chamber environments include:

- Reducing outgassing rates

- During ground based vacuum testing, such as thermal cycle tests, bake-out runs, and other Thermal Vacuum (TVAC) tests

- Limiting the use of cryogenic scavenger panels

- Cryogenic scavenger panels are normally used to trap outgassed contaminants that otherwise could condense on critical surfaces

- Helpful in reducing the pump down process

- When the chamber is being evacuated by the vacuum pump

- Achieving high vacuum and lower pressures more efficiently

- Than a pump could achieve on its own

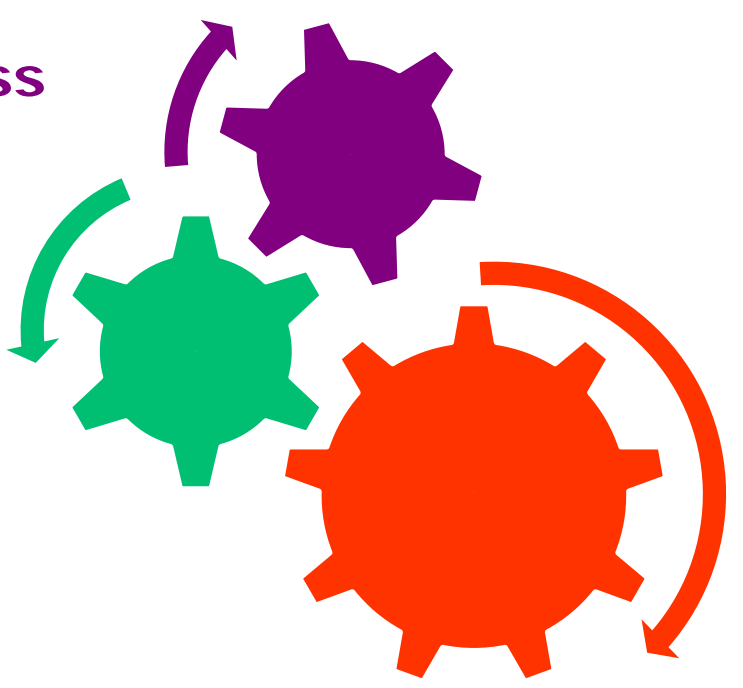




\section{Chamber A}

- Originally built in 1965 as part of the Space Environment Simulation Laboratory at NASA J ohnson Space Center (JSC) in Houston, Texas

- Best known for space environmental testing of the space capsules and equipment for NASA's Apollo missions with \& without the mission crew

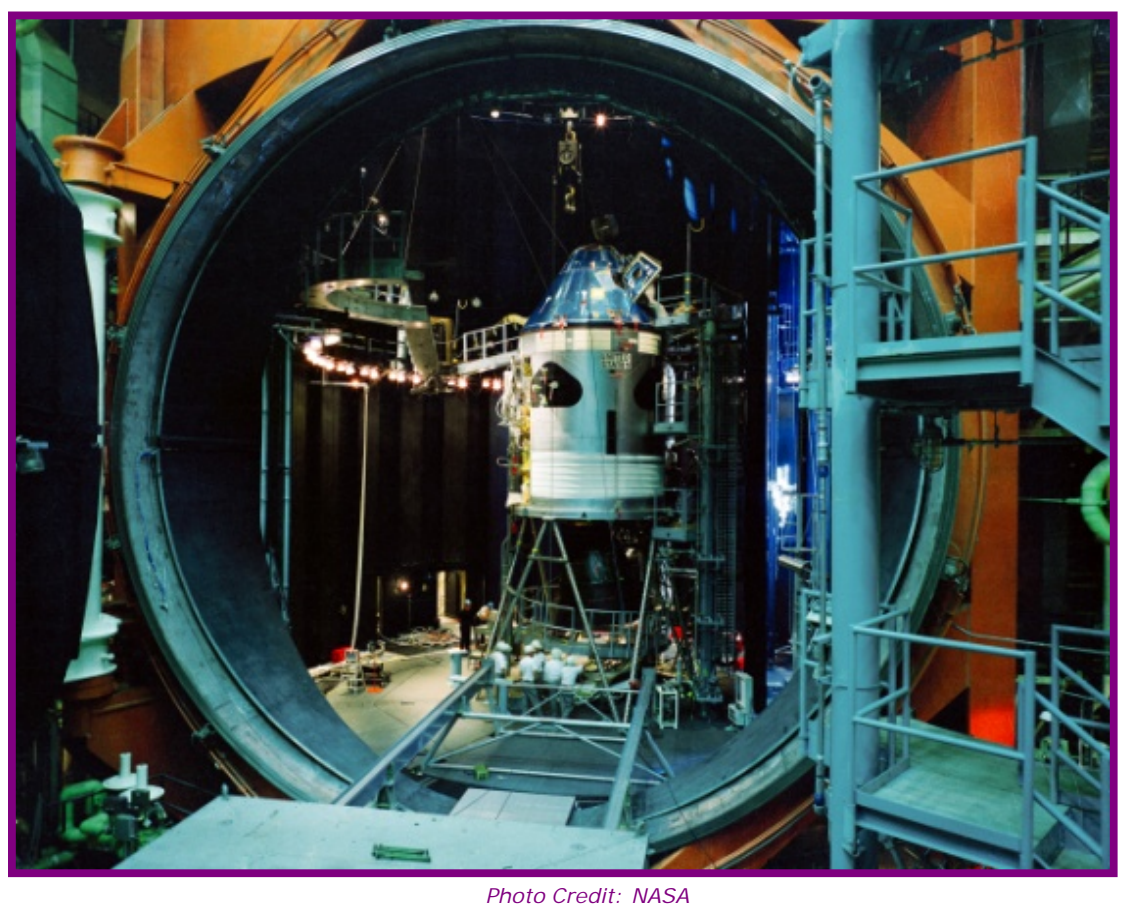

Apollo command and service module 2TV-1 in Chamber A for a full mission duration vacuum test in 1968

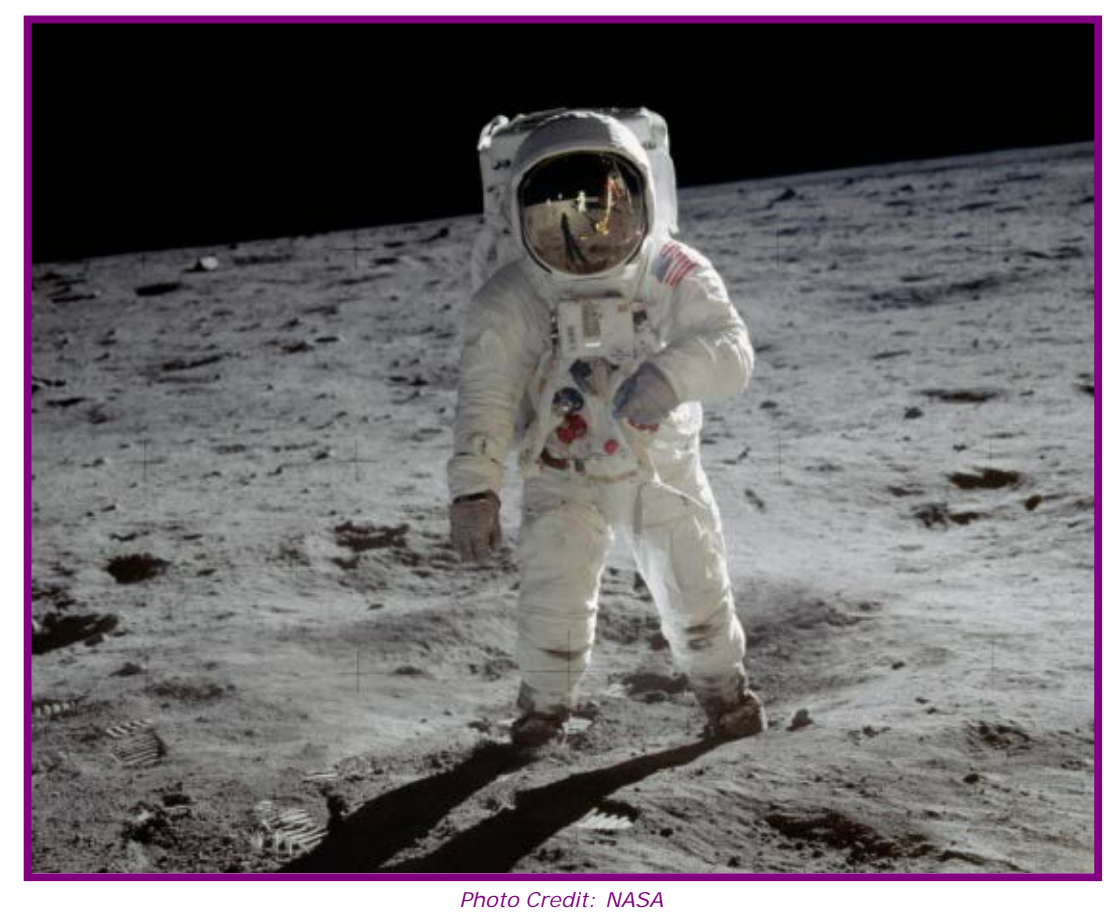

Astronaut Buzz Aldrin on the surface of the moon during Apollo 11 


\section{Chamber A}

\section{Dimensions:}

- $55 \mathrm{ft}$ diameter by $90 \mathrm{ft}$ tall vacuum chamber

- Has an interior volume of 400,000 cubic ft

- Has a hydraulically controlled 40 ft diameter 40 ton door

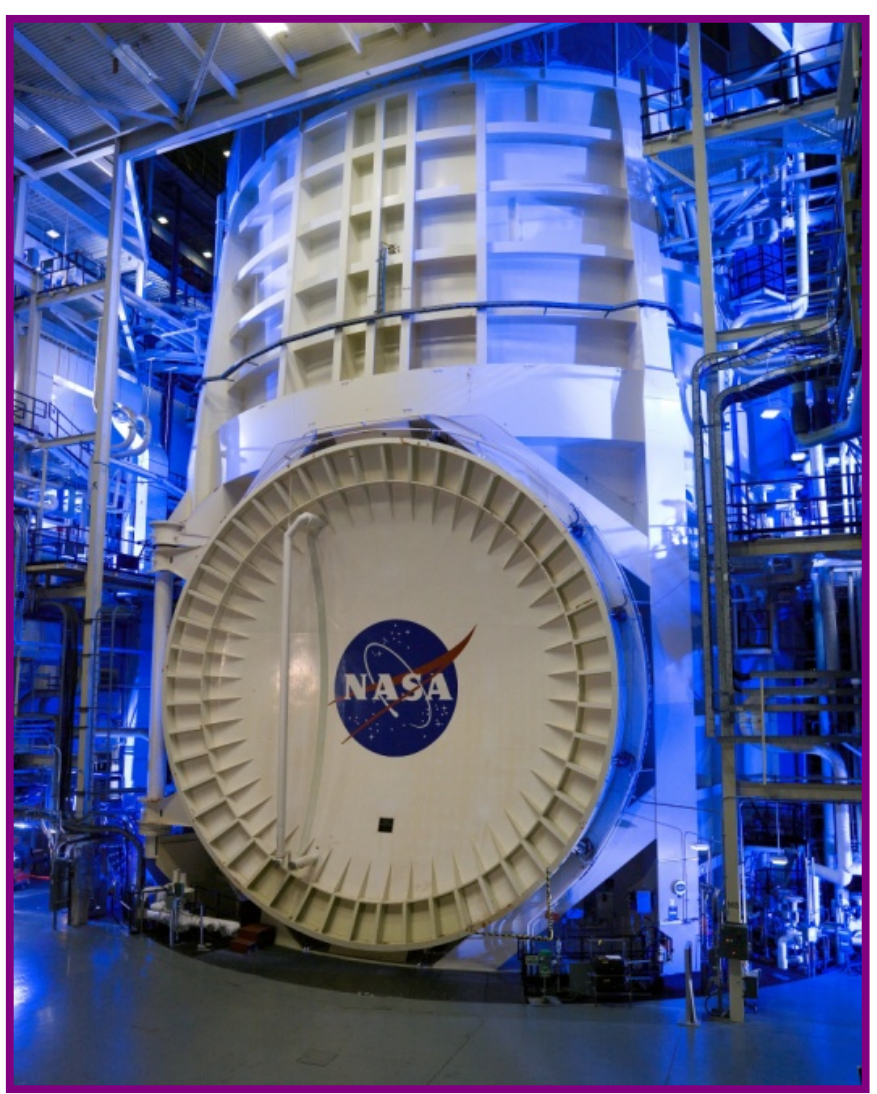

Photo Credit: NASA

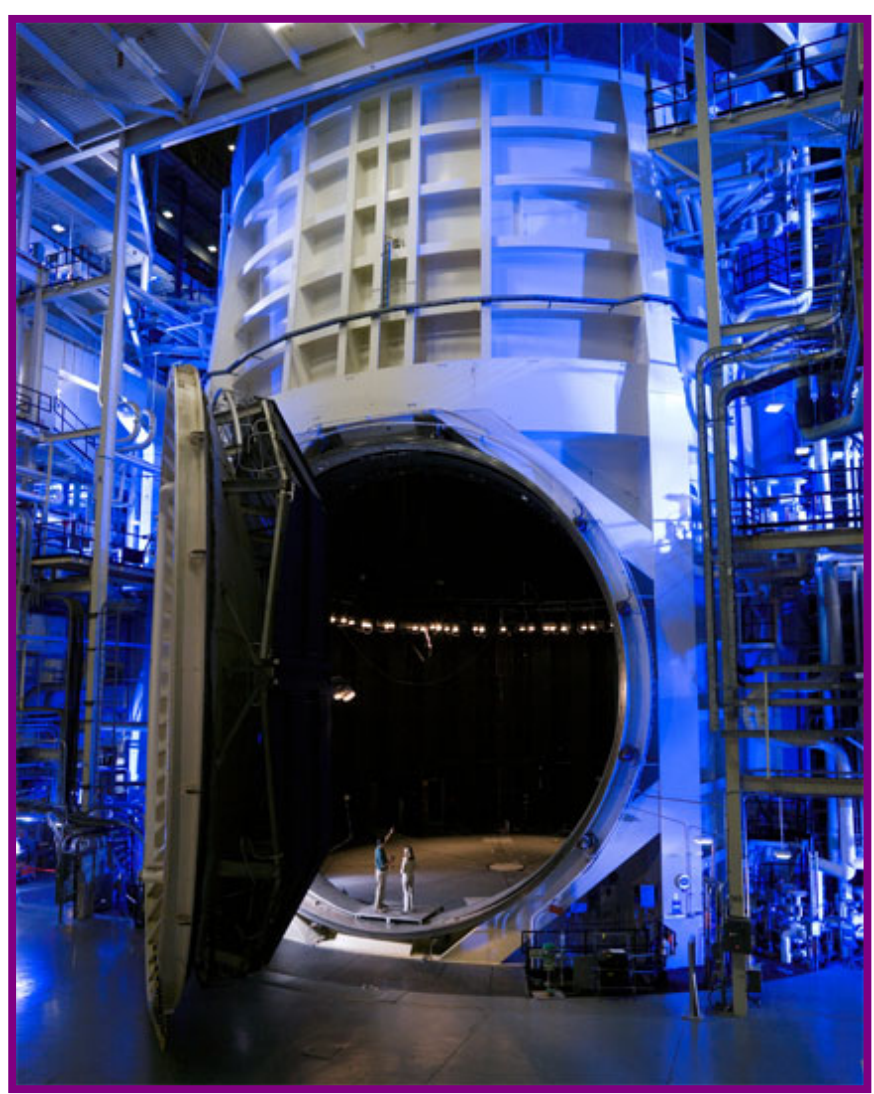

Photo Credit: NASA 


\section{Chamber A}

- Over the past several years, Chamber A has experienced significant upgrades to accommodate the arrival and testing of JWST in a space simulation environment

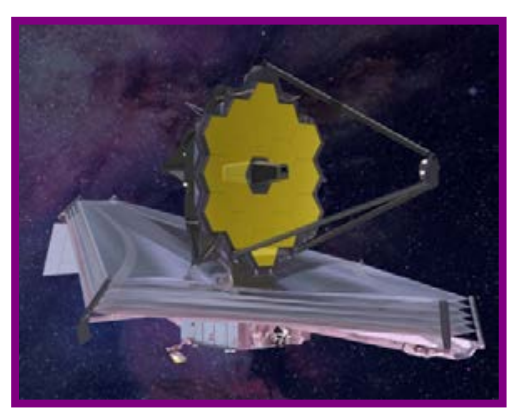

Photo Credit: NASA

\section{James Webb Space Telescope (J WST)}

- Successor to the Hubble Space Telescope

- Considered one of the most powerful infrared space telescopes ever to be built

- Has a $21.3 \mathrm{ft}$ diameter primary mirror

- Has a tennis court sized five layer sunshield

- Will experience a cryogenic environment near Sun-Earth L2 Lagrangian point (about 1 million miles from Earth)

- Chamber A upgrades include:

- Liquid Helium Shroud

- Capable of reaching cryogenic temperatures as low as $-262{ }^{\circ} \mathrm{C}$ to simulate the extremely cold environment that the telescope will be exposed to

- Clean Room

- Retrofitted to the test facility

- Pumping Systems

- Ultra-clean hydrocarbon-free high vacuum pumping systems

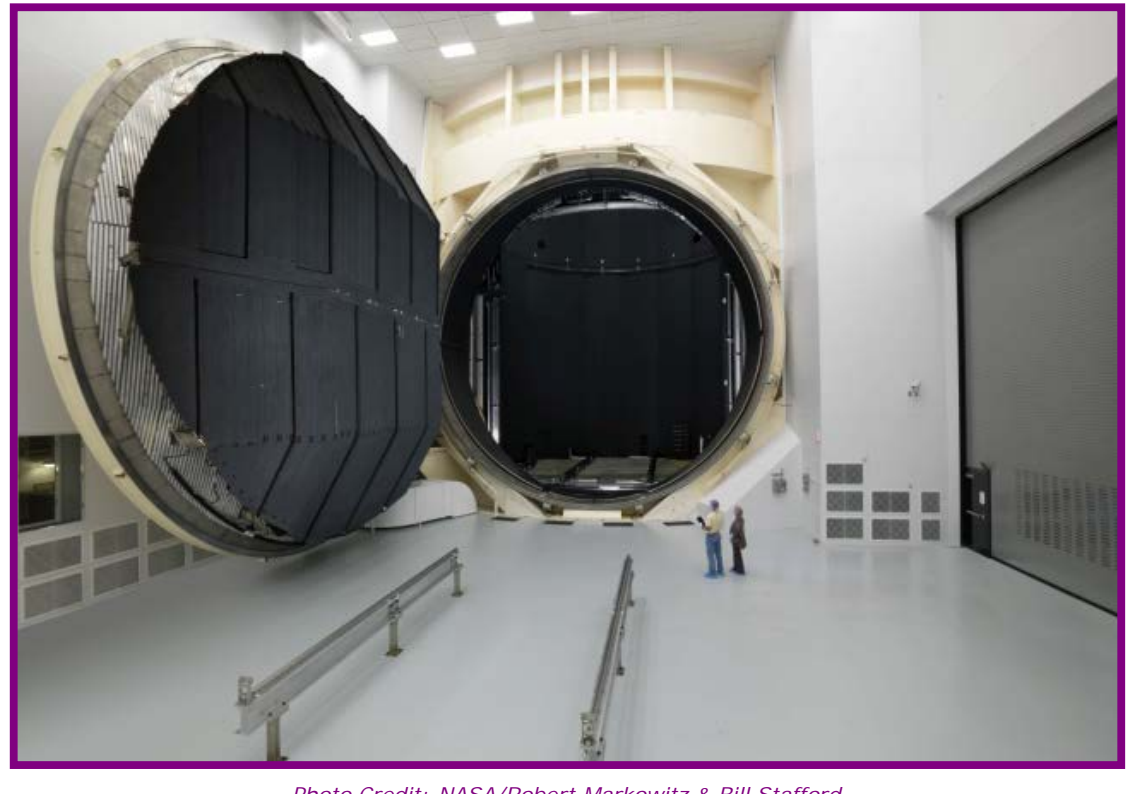

Photo Credit: NASA/Robert Markowitz \& Bill Stafford 


\section{Chamber A}

- With these impressive upgrades, Chamber A is now categorized as one of the largest high vacuum, cryogenic optical test chambers in the world!

- The Pathfinder model for JWST has been used for practicing ambient and vacuum testing that will be performed on the flight telescope

- Recently, MAC was implemented during the Pathfinder testing of the JWST Optical Ground Support Equipment (OGSE)

- MAC was used as a mitigation technique to capture molecular contamination within the upgraded Chamber A vacuum test facility

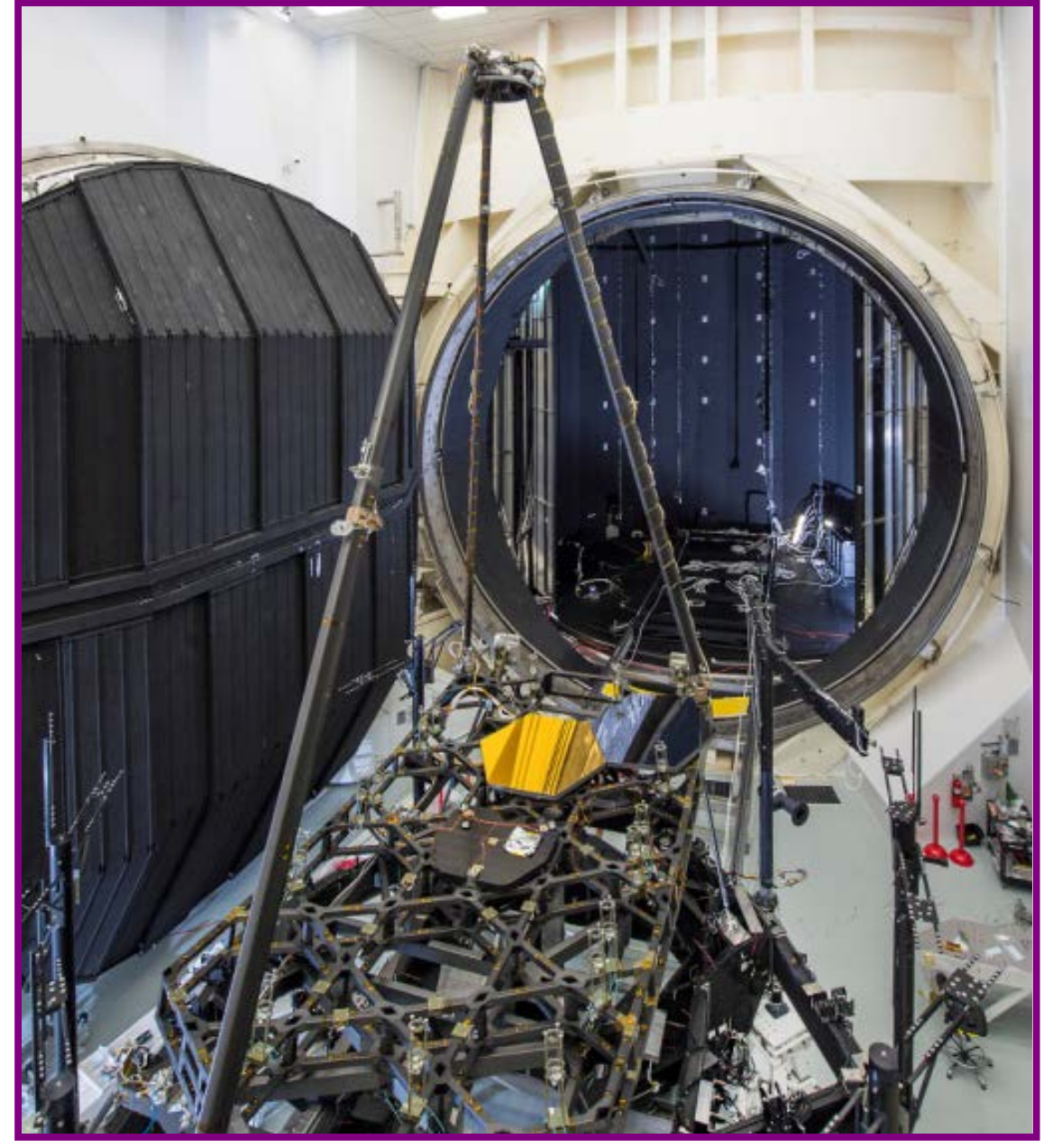

Photo Credit: NASA/Chris Gunn

Full-scale model of JWST Pathfinder shown entering the recently upgraded Chamber A for cryogenic testing in 2015 


\section{Molecular Contaminants}

- Due to Chamber A's history prior to JWST, molecular contaminants, such as silicones, still remain within the chamber plenum

- In particular, one of the main contaminant sources was the residual silicone from Dow Corning ${ }^{\circledR} 704$

- Also known as DC-704

- Single component, silicone based diffusion pump oil

- Commonly used for high vacuum systems

- Designed to work well with diffusion pumps due to its properties

- Low vapor pressure

- Low volatility

- Frequently used in Chamber A for Apollo mission testing

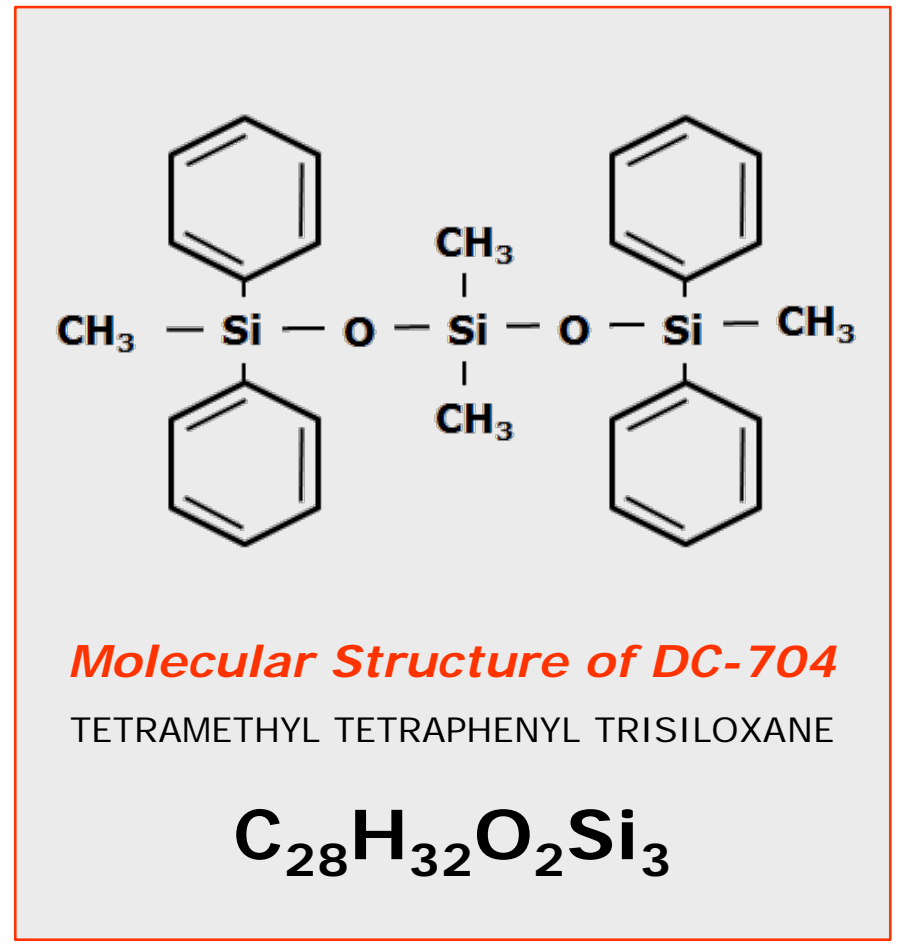




\section{Molecular Contaminants}

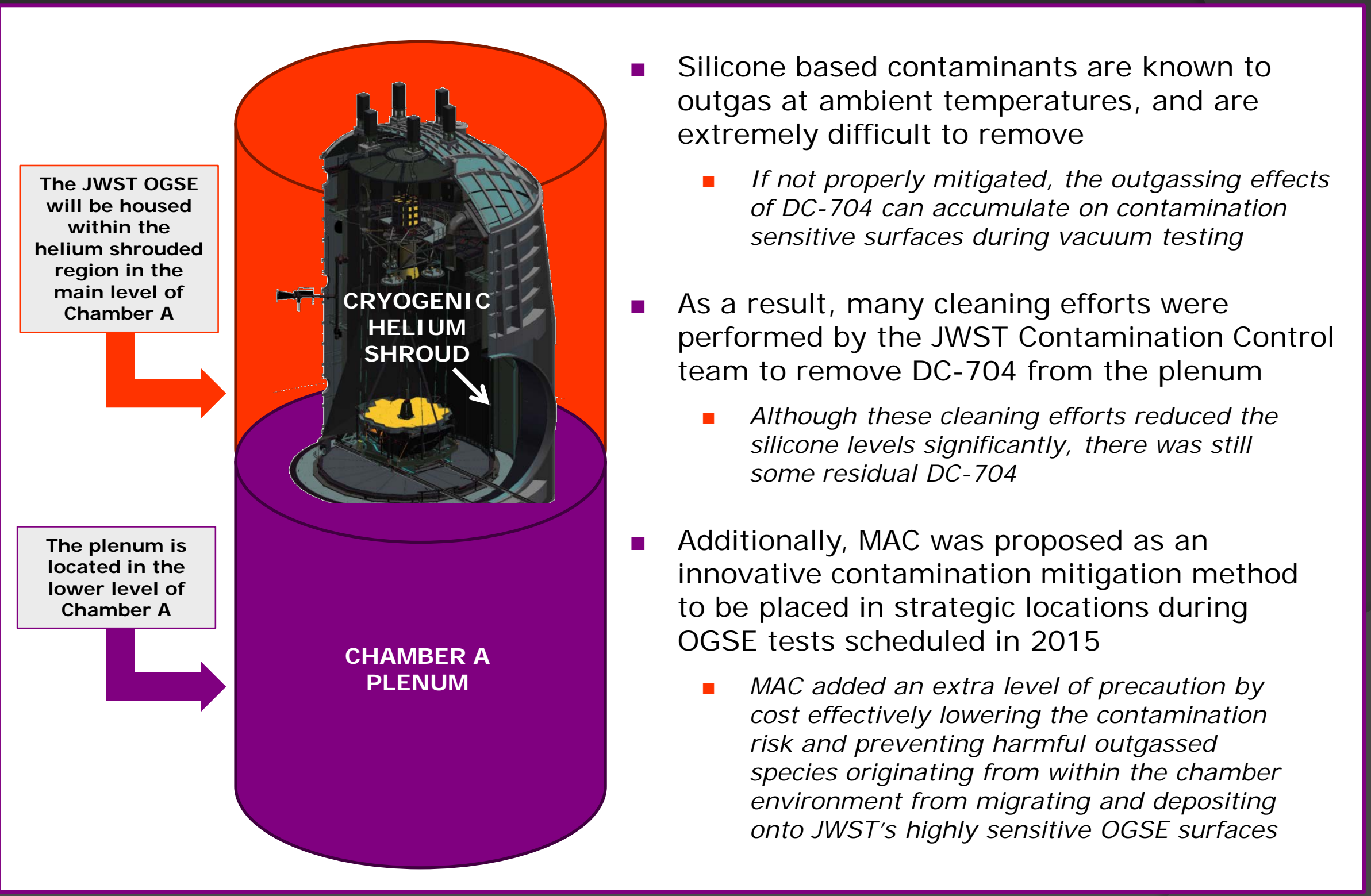




\section{Molecular Contaminants}

\section{"Proof of Concept" MAC Demonstration}

- Occurred prior to its first large scale application during JWST's Chamber A Commissioning Test in Oct 2014

- Four $1 \mathrm{ft}$ by $1 \mathrm{ft}$ white MAC aluminum panel samples were placed throughout the chamber at various locations to detect sources of contamination

- In particular, the migration of DC-704 from the plenum to the main level where the test equipment would be located during Pathfinder testing of the OGSE

- Chemical analysis of contaminated MAC samples indication for the collection of chemical species to the pores of the coating

- Demonstrated adsorption of various chemical species from within Chamber A, such as:

- Hydrocarbons

- DC-704 Silicone Based Diffusion Pump Oil

- Methyl Silicones

- Consequently, continued use of MAC for the OGSE tests in 2015 was planned to mainly capture DC-704, among other contaminants

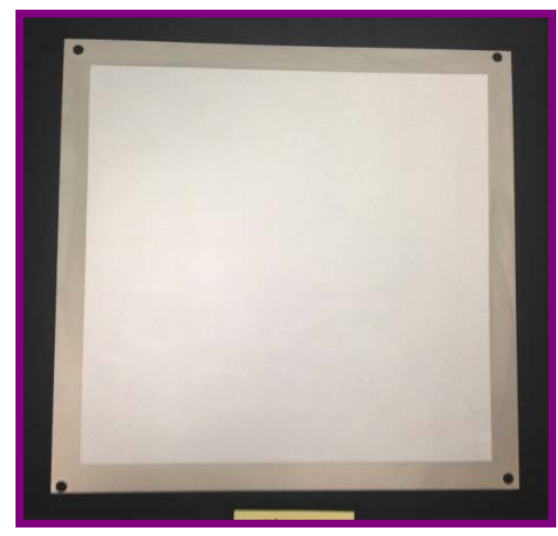

Photo Credit: NASA

Pristine White MAC 


\section{Application Efforts}

- Fabrication \& I nstallation

- MAC Barn Door Panels

- MAC Plenum Samples 


\section{Fabrication \& I nstallation}

\section{Fabrication Efforts}

- NASA GSFC custom designed 98 MAC samples in various sizes and substrate materials. This included a 6 month fabrication effort:

- December 2014 - April 2015 ( 4 months)

- August 2015 - September 2015 ( 2 months)

- Fabricated two sets of MAC samples

- MAC Barn Door Panels: planned for use in the main level

- MAC Plenum Samples: planned for use in the plenum

Both sets will be positioned in two different strategic locations within Chamber A to capture vacuum chamber contamination and prevent them from entering the test environment where the OGSE is housed

\section{I nstallation Efforts}

- Installed prior to the start of the two JWST Pathfinder testing efforts of the OGSE

- OGSE-1: First OGSE test from May 2015 - June 2015

- OGSE-2: Second OGSE test from September 2015 - October 2015

- MAC samples were exposed to the vacuum chamber environment

- During installation activities prior to the test

- Throughout the duration of the two tests

- MAC samples were removed and shipped back to NASA GSFC after the completion of the OGSE tests for chemical analysis and further testing 


\section{MAC Barn Door Panels}

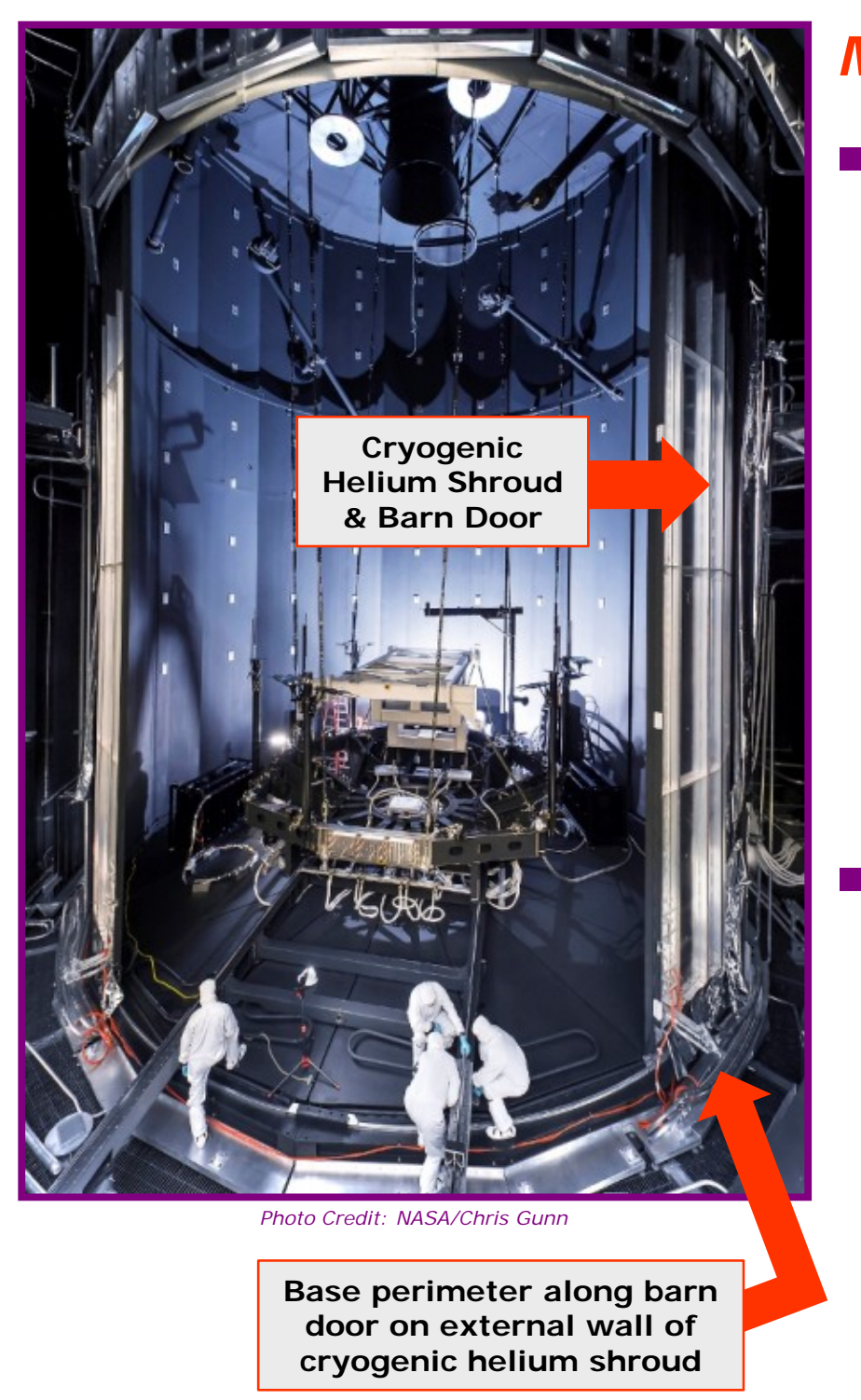

Main Level of Chamber A

n "Barn Door" - Cryogenic Helium Shroud

- During Pathfinder testing of the OGSE, the cryogenic helium shroud reaches temperatures:

- As cold as $-241{ }^{\circ} \mathrm{C}$

- As warm as room temperature

- Internal wall of shroud

- Painted with a thermal /optical black coating

- External wall of shroud

- Made of an aluminum finish

\section{Proposed MAC Location}

- Against the base of the external wall on the shroud to cover some of the exposed gaps near the perimeter along the barn door of Chamber $A$

- To capture vacuum chamber contaminants that may have migrated from the plenum and prevent them from depositing on the sensitive JWST test equipment housed internal to the cryogenic helium shroud 


\section{MAC Barn Door Panels}

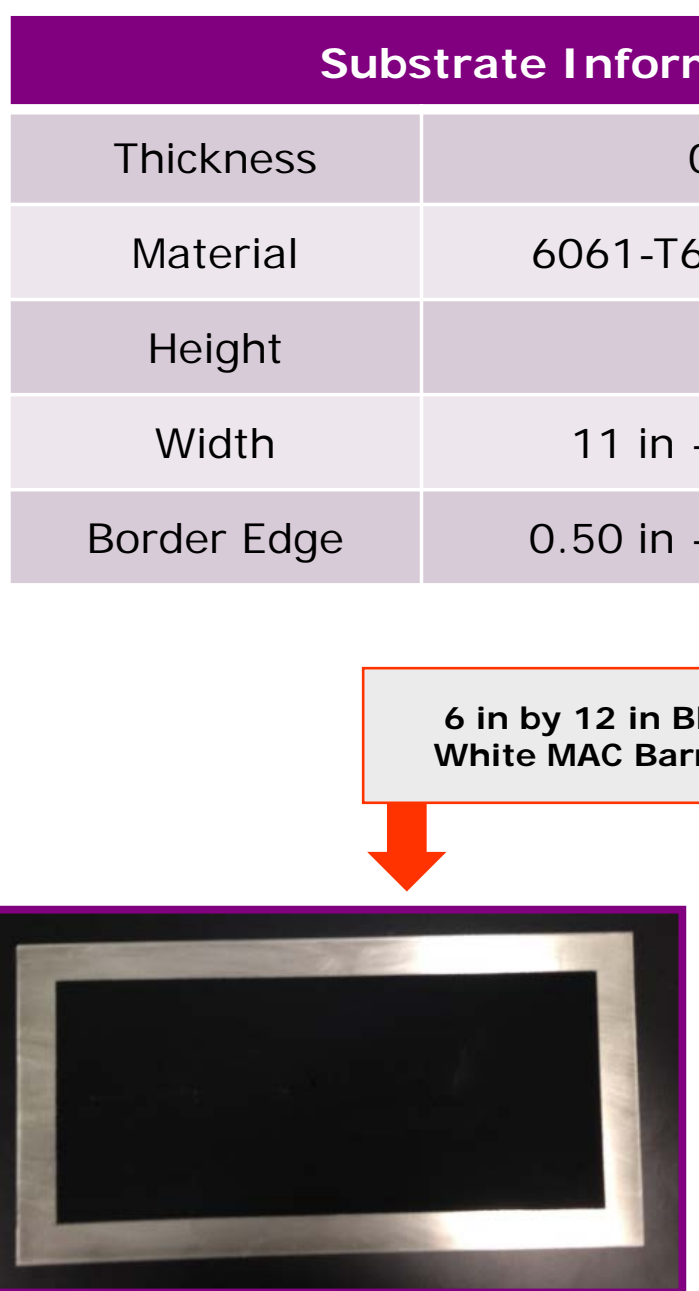

Photo Credit: NASA
0.0625 in

6061-T6 Aluminum Alloy

6 in

1 in - 46 in (varies)

0.50 in - 0.75 in (varies)

6 in by 12 in Black MAC and White MAC Barn Door Panels

Border was implemented on samples to reduce possible coating damage due to handling and installation activities

Installation of a white MAC barn door panel on the external wall of the cryogenic helium shroud covering the gap along the base perimeter of Chamber A 


\section{MAC Barn Door Panels}

\section{Fabrication Efforts}

- Fabricated a total of 65 samples $\left(\sim 57 \mathrm{ft}^{2}\right)$

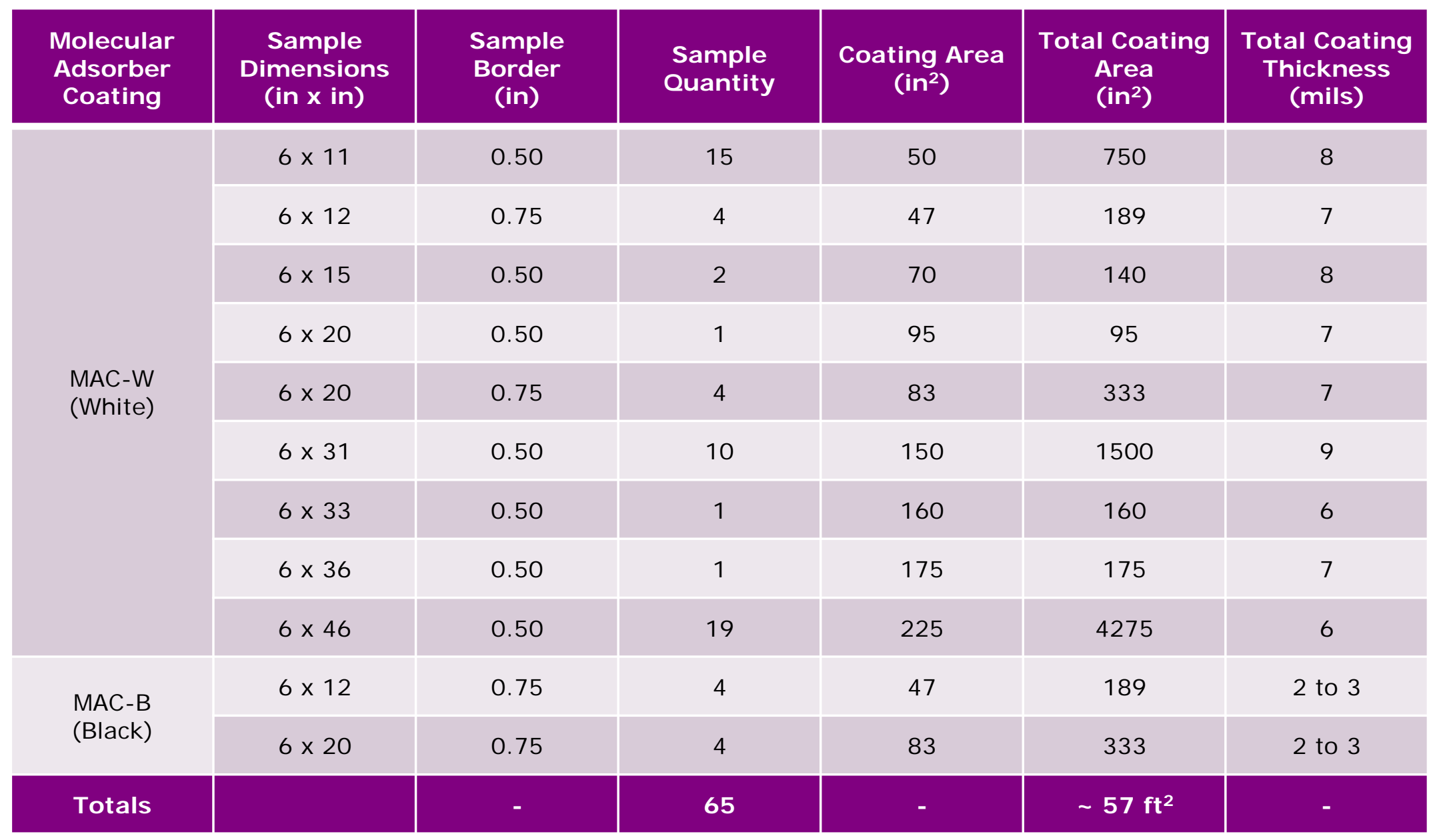




\section{MAC Barn Door Panels}

\section{I nstallation Efforts}

- Installed a total of 53 samples $\left(\sim 50 \mathrm{ft}^{2}\right)$ for both tests

\begin{tabular}{|c|c|c|c|c|c|}
\hline \multicolumn{3}{|c|}{$\begin{array}{l}\text { OGSE- } 1 \\
\text { I nstallation Date: May } 2015\end{array}$} & \multicolumn{3}{|c|}{$\begin{array}{l}\text { OGSE-2 } \\
\text { Installation Date: September } 2015\end{array}$} \\
\hline $\begin{array}{c}\text { Sample } \\
\text { Dimensions } \\
\text { (in } x \text { in) }\end{array}$ & Quantity & $\begin{array}{l}\text { Total Coating } \\
\text { Area }\left(\mathrm{in}^{2}\right)\end{array}$ & $\begin{array}{c}\text { Sample } \\
\text { Dimensions } \\
\text { (in } x \text { in) }\end{array}$ & Quantity & $\begin{array}{l}\text { Total Coating } \\
\text { Area }\left(\mathrm{in}^{2}\right)\end{array}$ \\
\hline $6 \times 11$ & 9 & 450 & $6 \times 12$ & 5 & 236 \\
\hline $6 \times 15$ & 1 & 70 & $6 \times 15$ & 1 & 70 \\
\hline $6 \times 20$ & 1 & 95 & $6 \times 20$ & 7 & 583 \\
\hline $6 \times 31$ & 6 & 900 & $6 \times 31$ & 5 & 750 \\
\hline $6 \times 33$ & 1 & 160 & $6 \times 46$ & 6 & 1350 \\
\hline $6 \times 46$ & 11 & 2475 & - & - & - \\
\hline Totals & 29 & $\sim 29 \mathrm{ft}^{2}$ & Totals & 24 & $\sim 21 \mathrm{ft}^{2}$ \\
\hline
\end{tabular}




\section{MAC Plenum Samples}

\section{Lower Level of Chamber A}

\section{Plenum of Chamber A}

- Encompasses a large volume

- Located beneath the chamber

- Classified as a confined space area

- During Pathfinder testing of the OGSE, plenum contamination (DC-704) may migrate towards the main level cryogenic helium shroud, and ultimately find a path into the chamber where the sensitive equipment will be placed

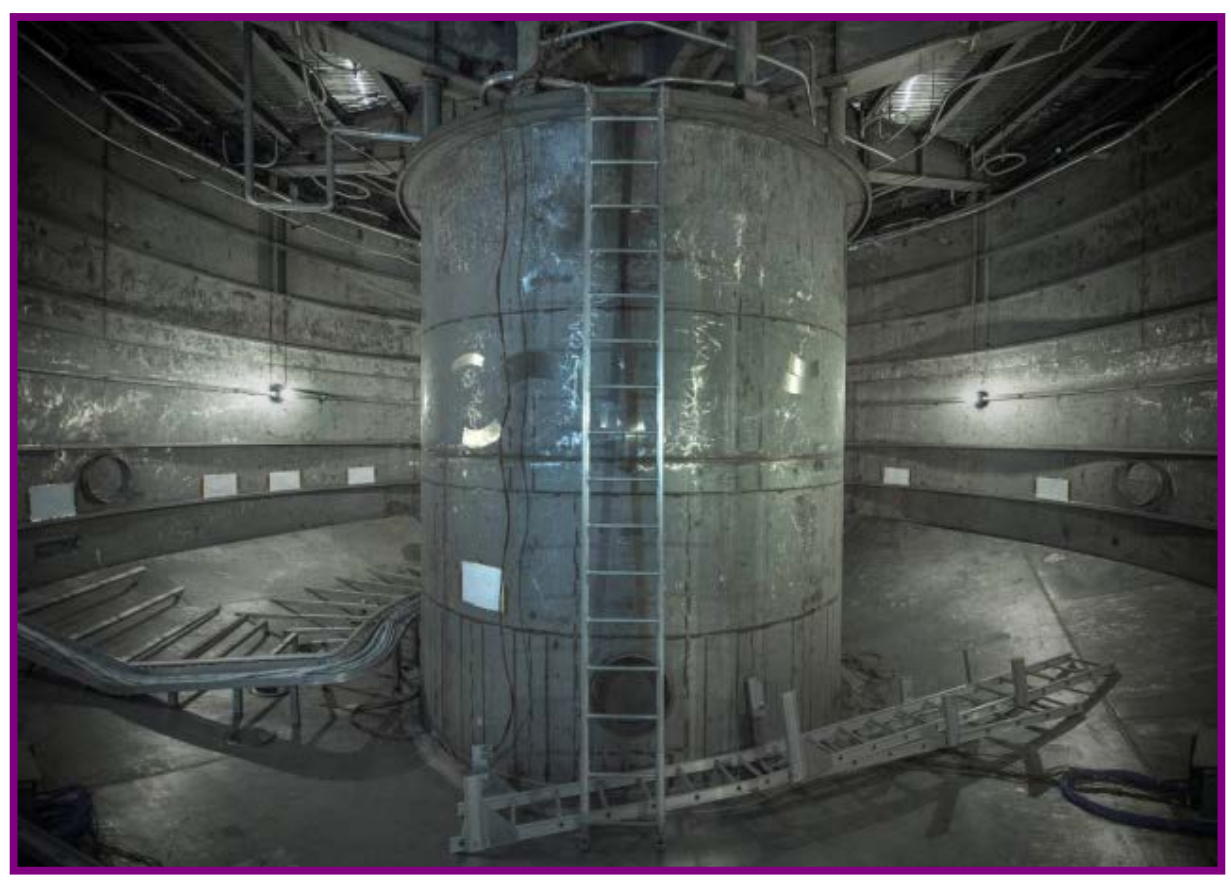

\section{Proposed MAC Location}

- MAC samples were placed against the walls of the plenum to capture contamination at its source

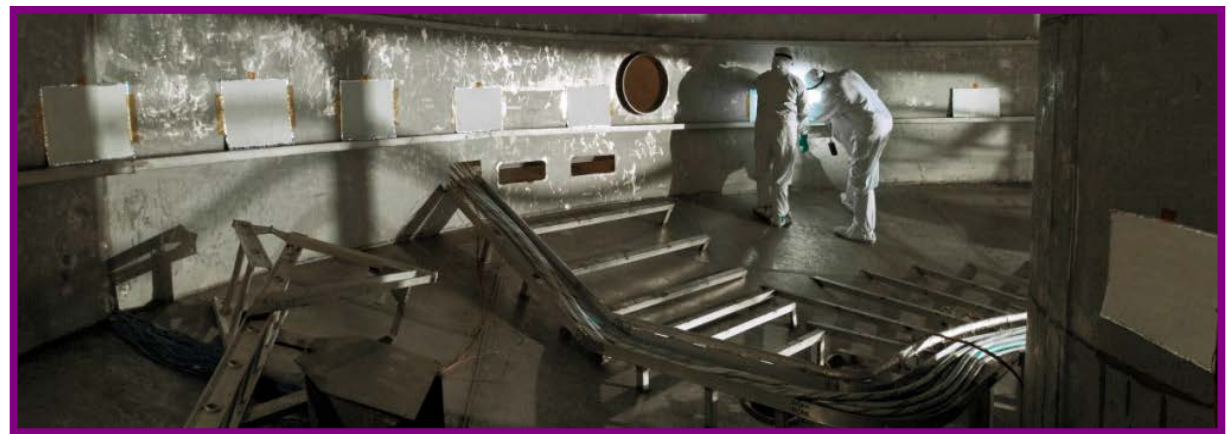

As shown, NASA GSFC installed MAC samples on the walls of the plenum in the Chamber A test facility prior to the start of the two OGSE tests 


\section{MAC Plenum Samples}

- Variety of flexible substrates were explored for the plenum samples

\section{- Aluminum Foil}

- Used primarily during OGSE-1 tests

- At times, handling was a challenge due to the low tear resistance of the material

- Kapton

- Limited use during OGSE-1 tests

- Aluminum Laminate Materials

- Used primarily during OGSE-2 tests

- NepTape ${ }^{\circledR} 1026$

- Typically used in industry as a second shield in multi-shielded Local Area Network (LAN) coaxial cables

- Its layered structure allows the material to exhibit a higher tear resistance, and consequently is more flexible and easier to handle than aluminum foil coated MAC samples

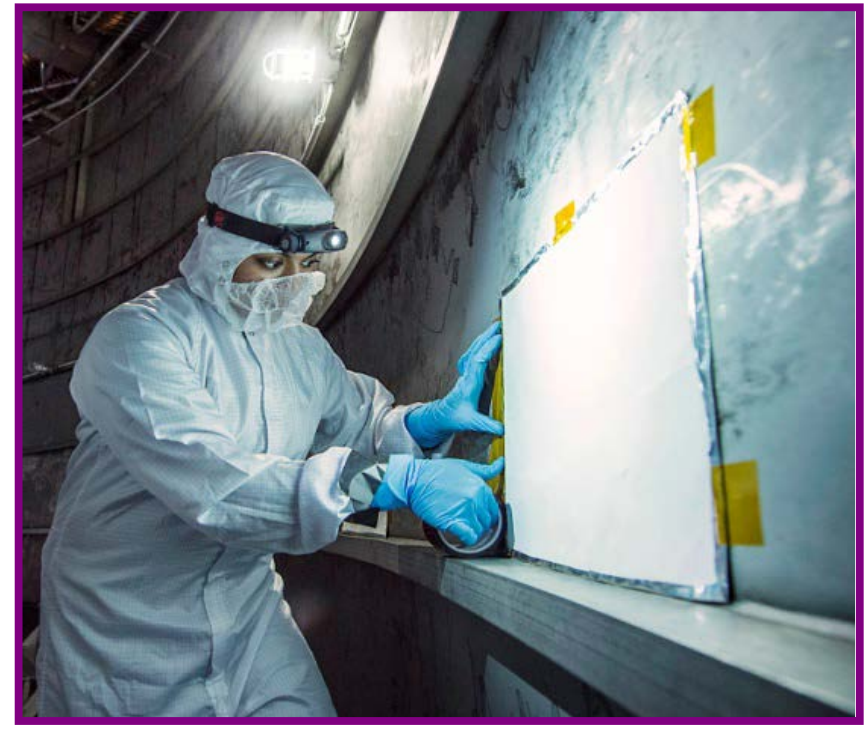

Photo Credit: NASA/Chris Gunn

A thin border less than 0.25 in was implemented on the plenum samples to avoid direct contact with the coating during handling and installation.

This border provided a location to adhere Kapton tape to during its placement on the plenum wall.

Construction of NepTape ${ }^{\circledR} 1026$

1 mil Aluminum Foil

0.92 mil Polyester Film

1 mil Aluminum Foil 


\section{MAC Plenum Samples}

\section{Fabrication Efforts}

- Fabricated a total of 33 samples $\left(\sim 60 \mathrm{ft}^{2}\right)$

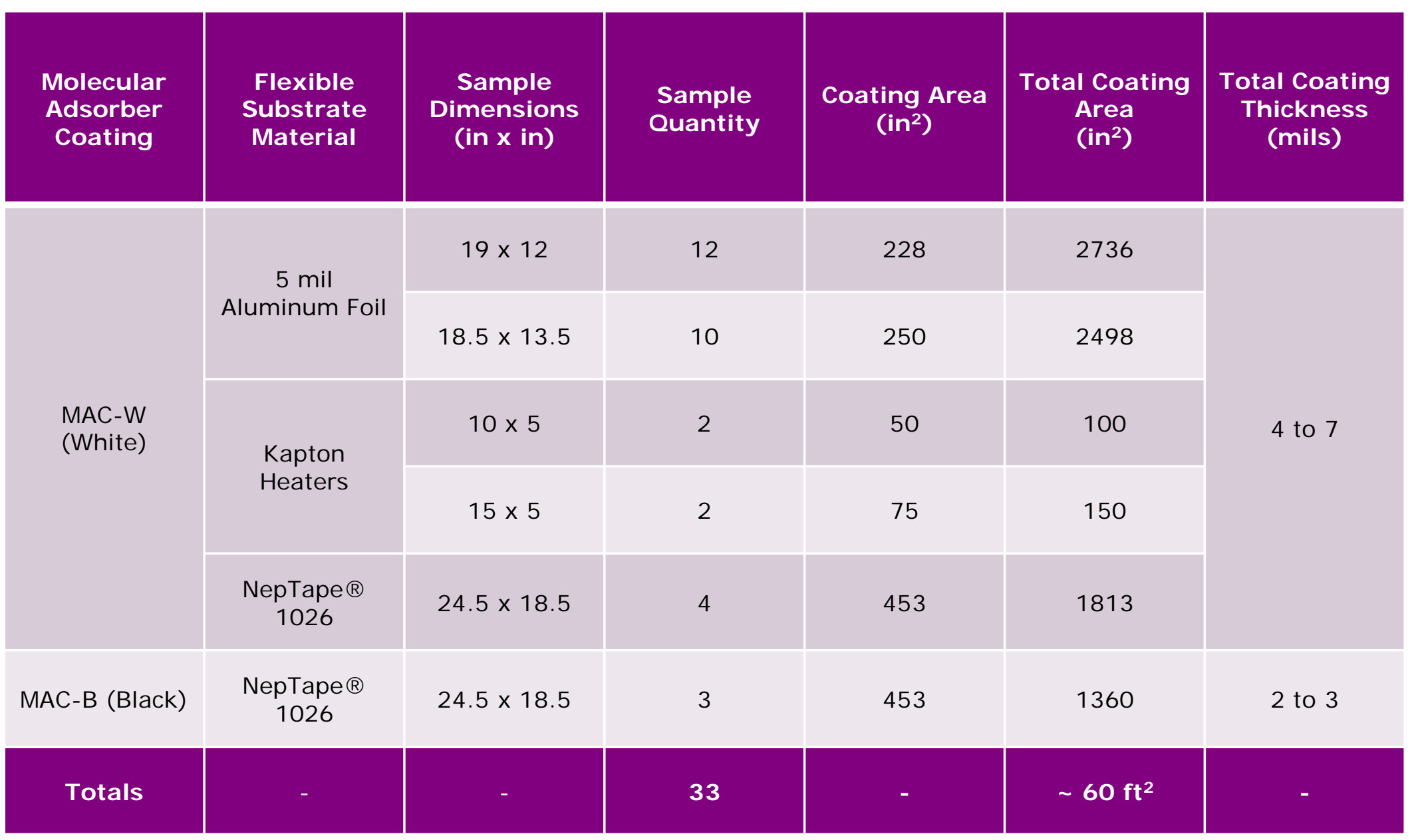




\section{MAC Plenum Samples}

\section{I nstallation Efforts}

- Installed a total of 33 samples $\left(\sim 60 \mathrm{ft}^{2}\right)$ for both tests

\begin{tabular}{|c|c|c|c|c|c|c|c|}
\hline \multicolumn{4}{|c|}{$\begin{array}{l}\text { OGSE- } 1 \\
\text { I nstallation Date: May } 2015\end{array}$} & \multicolumn{4}{|c|}{$\begin{array}{l}\text { OGSE-2 } \\
\text { I nstallation Date: September } 2015\end{array}$} \\
\hline $\begin{array}{l}\text { Flexible } \\
\text { Substrate } \\
\text { Material }\end{array}$ & $\begin{array}{c}\text { Sample } \\
\text { Dimensions } \\
\text { (in } x \text { in) }\end{array}$ & Quantity & $\begin{array}{l}\text { Total } \\
\text { Coating } \\
\text { Area } \\
\left(\text { in }^{2}\right)\end{array}$ & $\begin{array}{c}\text { Flexible } \\
\text { Substrate } \\
\text { Material }\end{array}$ & $\begin{array}{c}\text { Sample } \\
\text { Dimensions } \\
\text { (in } x \text { in) }\end{array}$ & Quantity & $\begin{array}{l}\text { Total } \\
\text { Coating } \\
\text { Area } \\
\left(\mathrm{in}^{2}\right)\end{array}$ \\
\hline \multirow{2}{*}{$\begin{array}{c}5 \text { mil } \\
\text { Aluminum } \\
\text { Foil }\end{array}$} & $19 \times 12$ & 12 & 2736 & \multirow{4}{*}{$\begin{array}{l}\text { NepTape }{ }^{\circledR} \\
1026\end{array}$} & $24.5 \times 18.5$ & 7 & 3173 \\
\hline & $18.5 \times 13.5$ & 10 & 2498 & & - & - & - \\
\hline \multirow{2}{*}{$\begin{array}{l}\text { Kapton } \\
\text { Heaters }\end{array}$} & $10 \times 5$ & 2 & 100 & & - & - & - \\
\hline & $15 \times 5$ & 2 & 150 & & - & - & - \\
\hline Totals & - & 26 & $\sim 38 \mathrm{ft}^{2}$ & Totals & - & 7 & $\sim 22 \mathrm{ft}^{2}$ \\
\hline
\end{tabular}




\section{Testing Efforts}

- Molecular Capacitance Testing

- Chemical Analysis

- Closing Remarks 


\section{Molecular Capacitance}

\section{Molecular Adsorption Capacity}

- Also referred to as "molecular capacitance"

- Defined as the measure of the coating's capability to adsorb or entrap outgassed materials (i.e. molecular contaminants)

- Dependent on parameters, such as:

- Coating Thickness

- Surface Area Coverage

- Type of Contaminant

- Duration of Exposure to Contaminant
EFFECT OF COATING THI CKNESS ON MAC ADSORPTI ON CAPABI LITIES

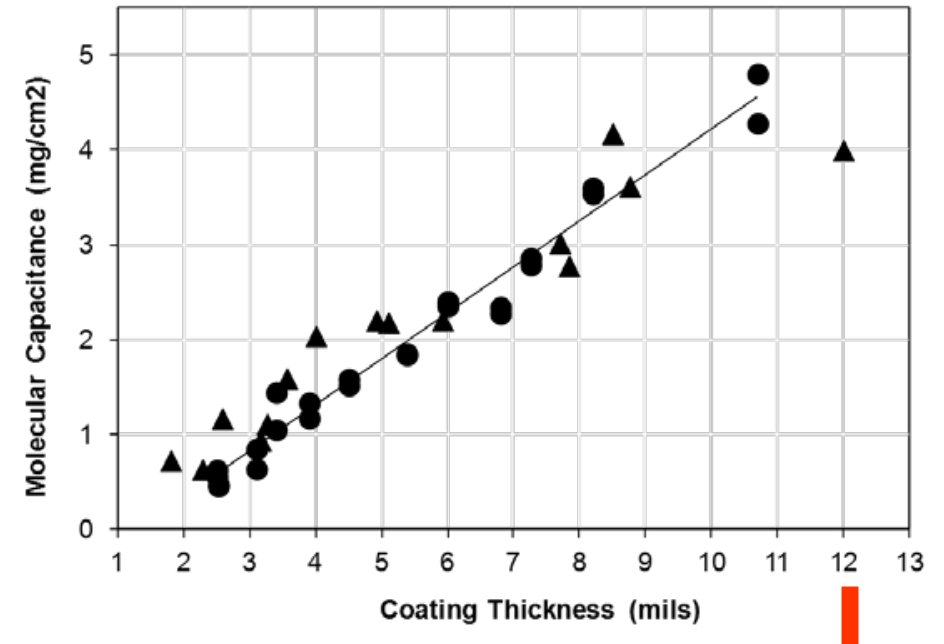

- Calculated gravimetrically, based on mass changes in the coating due to exposure to the contaminant source

- Past test efforts confirmed that the molecular adsorption capacity of MAC is directly proportional to coating thickness

- This set of experimental data used STEARYL ALCOHOL at $45{ }^{\circ} \mathrm{C}$ as a model contaminant source at exposures between 88 and 160 hours

- Also known as 1-octadecanol

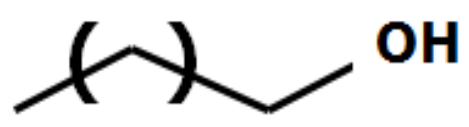

16
- An organic fatty alcohol commonly found in consumer products, such as lubricants, resins, cosmetics, shampoos, perfumes, emulsifiers, and ointments

- Long chain hydrocarbon that is representative of commonly outgassed materials found in spaceflight applications
Stearyl alcohol was selected for these molecular capacitance tests because it is a highly volatile condensable material with a constant vapor pressure for a given temperature, which in turn results in a constant contaminant source rate for baseline comparison purposes 


\section{Molecular Capacitance}

- Prior to MAC fabrication, an additional molecular capacitance test was performed to determine if the coating specifically adsorbs DC-704

- DC-704 is a more complex high molecular weight chemical species than the previously tested model contaminant (stearyl alcohol)

- Has a higher molecular weight; about 1.8 times greater

- Has a lower vapor pressure and lower volatility properties

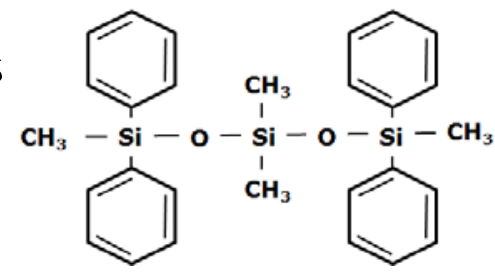

\begin{tabular}{|c|c|c|c|c|c|}
\hline $\begin{array}{c}\text { Type of } \\
\text { Contaminant }\end{array}$ & $\begin{array}{c}\text { Contaminant } \\
\text { Source }\end{array}$ & $\begin{array}{c}\text { Chemical } \\
\text { Name }\end{array}$ & $\begin{array}{c}\text { Chemical } \\
\text { Formula }\end{array}$ & $\begin{array}{c}\text { Molecular } \\
\text { Weight }\end{array}$ & $\begin{array}{c}\text { Vapor Pressure } \\
\text { at 25 }{ }^{\circ} \mathbf{C}\end{array}$ \\
\hline $\begin{array}{c}\text { Long Chain } \\
\text { Hydrocarbon }\end{array}$ & Stearyl Alcohol & 1-octadecanol & $\mathrm{C}_{18} \mathrm{H}_{38} \mathrm{O}$ & $270.5 \mathrm{~g} / \mathrm{mol}$ \\
\hline $\begin{array}{c}\text { Silicone Based } \\
\text { Compound }\end{array}$ & $\begin{array}{c}\text { DC-704 Diffusion } \\
\text { Pump Oil }\end{array}$ & $\begin{array}{c}\text { tetramethyl } \\
\text { tetraphenyl } \\
\text { trisiloxane }\end{array}$ & $\mathrm{C}_{28} \mathrm{H}_{32} \mathrm{O}_{2} \mathrm{Si}_{3}$ & $484.8 \mathrm{~g} / \mathrm{mol}$ \\
\hline
\end{tabular}

- Due to the complexity of the silicone based single component fluid, test parameters such as temperature, were modified to reduce the test duration

- 18 white MAC samples with a total coating thickness of 6.1 mils

\begin{tabular}{|c|c|c|c|c|}
\hline Contaminant Source & Source Temperature & Exposure Time & Coating Thickness & Adsorption Capacity \\
\hline Stearyl Alcohol & $45^{\circ} \mathrm{C}$ & $88 \mathrm{hrs}-160 \mathrm{hrs}$ & $6.1 \mathrm{mils}$ & $\sim 2.3 \mathrm{mg} / \mathrm{cm}^{2}$ \\
\hline $\begin{array}{c}\text { DC-704 Diffusion } \\
\text { Pump Oil }\end{array}$ & $70^{\circ} \mathrm{C}$ & $115 \mathrm{hrs}$ & $6.1 \mathrm{mils}$ & $\sim 1.2 \mathrm{mg} / \mathrm{cm}^{2} *$ \\
\hline
\end{tabular}

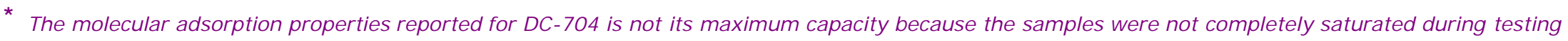




\section{Molecular Capacitance}

\section{Quartz Crystal Microbalance (QCM) Collection Rate Response and Temperature Data}

using DC-704 Diffusion Pump Oil as the Contaminant Source

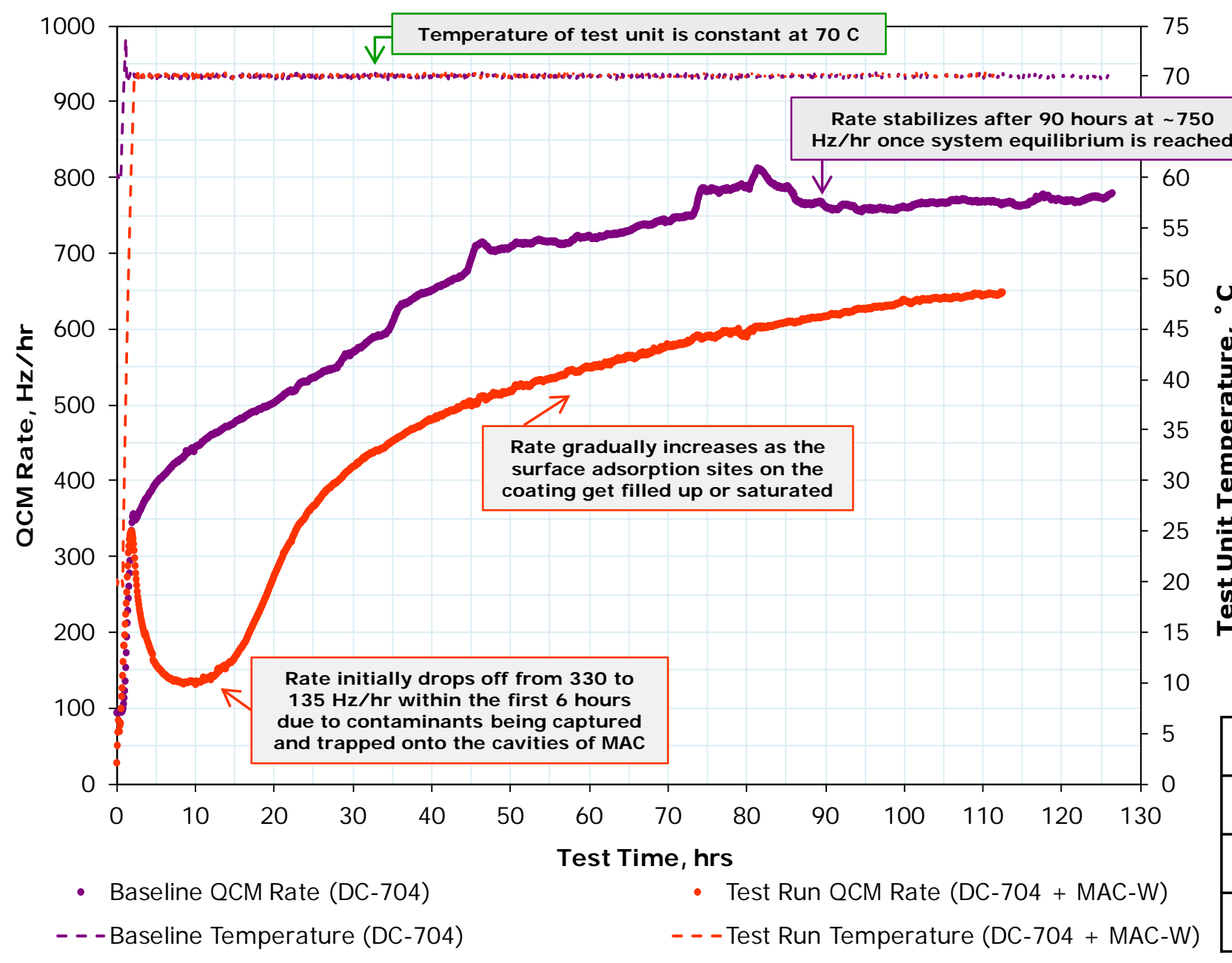

“I deal” Experimental Scenario:

- The test run is expected to approach the baseline when the pore sites on the coating become saturated and can no longer easily adsorb the flux of contaminants. When this state is achieved, the test system behaves as if MAC samples are no longer present during the test run.

\section{Test Run Status:}

- Due to time constraints, the test run was brought to an end at $\sim 115$ hours. As a result, it did not approach the baseline. This indicated that the MAC samples have not yet reached saturation. If the test was continued for a longer duration, the MAC samples will continue to adsorb until the majority of the pore sites are filled.

\begin{tabular}{|c|c|c|}
\cline { 2 - 3 } \multicolumn{1}{c|}{} & $\begin{array}{c}\text { Baseline } \\
\text { Run }\end{array}$ & $\begin{array}{c}\text { Test } \\
\text { Run }\end{array}$ \\
\hline DC-704 & $\boldsymbol{V}$ & $\boldsymbol{V}$ \\
\hline MAC & & $70^{\circ} \mathrm{C}$ \\
\hline Temperature & $70^{\circ} \mathrm{C}$ & $\sim 115 \mathrm{hrs}$ \\
\hline Duration & $\sim 127 \mathrm{hrs}$ & $\sim 110$ \\
\hline
\end{tabular}




\section{Chemical Analysis}

\section{Vacuum Desorption Bake-Out Method}

- In industry, a common practice used to regenerate microporous materials, such as zeolite, involve high temperature vacuum bake-outs between $175-315{ }^{\circ} \mathrm{C}$

- Performed on a single aluminum foil white MAC sample that had been deployed in the Chamber A plenum environment during OGSE-1 (May 2015)

- Small piece (4 in by 3.5 in) was cut from Sample PM 13

- Total coating thickness of 7 mils

- Constructed a bake-out box

- Substrate Type: 6061-T6 aluminum alloy

- Substrate Thickness: 0.050 in

- Dimensions of 216 cubic in

- Baseline run without the MAC plenum sample was performed to determine the chamber background contamination that would deposit on the Liquid Nitrogen (LN2) cold plate

- Test configuration was jacketed with aluminum foil during testing to limit the chamber background deposition on the cold plate

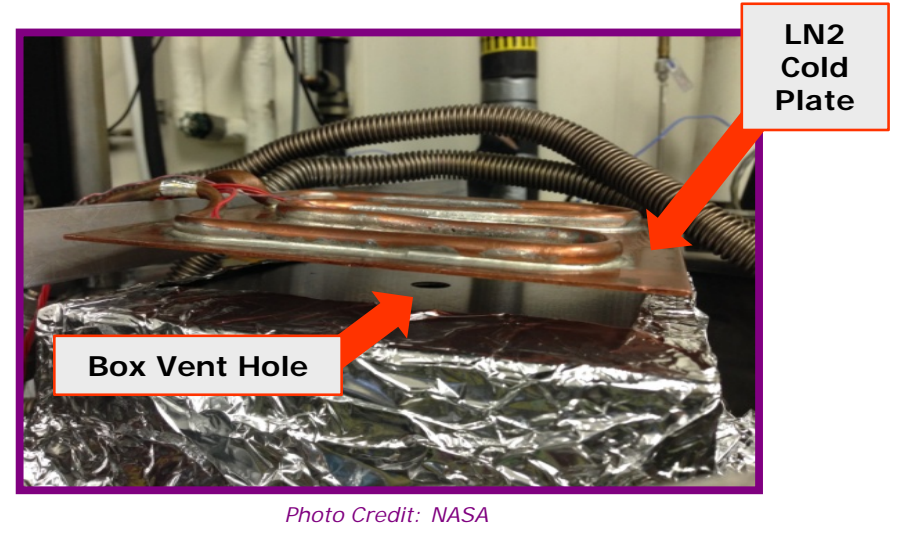

Vent hole was made for desorbed contaminants to exit the box and directly deposit on the LN2 cold plate above

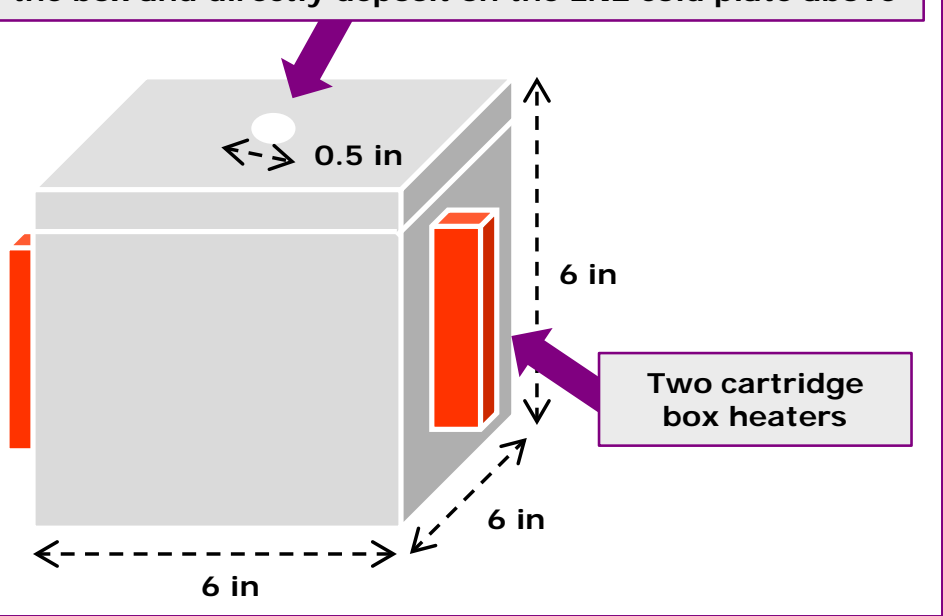




\section{Chemical Analysis}

- Cold plate was immediately rinsed twice after repressing the chamber

- First rinse was with Isopropyl Alcohol (IPA)

- Second rinse was with Chloroform

- Rinsates were transferred to separate pre-weighed dishes and allowed to evaporate to dryness

- Remaining Non-Volatile Residue (NVR) was weighed and analyzed using two methods:

- Fourier Transform Infrared Spectroscopy (FTIR)

- Pyrolysis-Gas Chromatography / Mass Spectrometry (GC/MS)

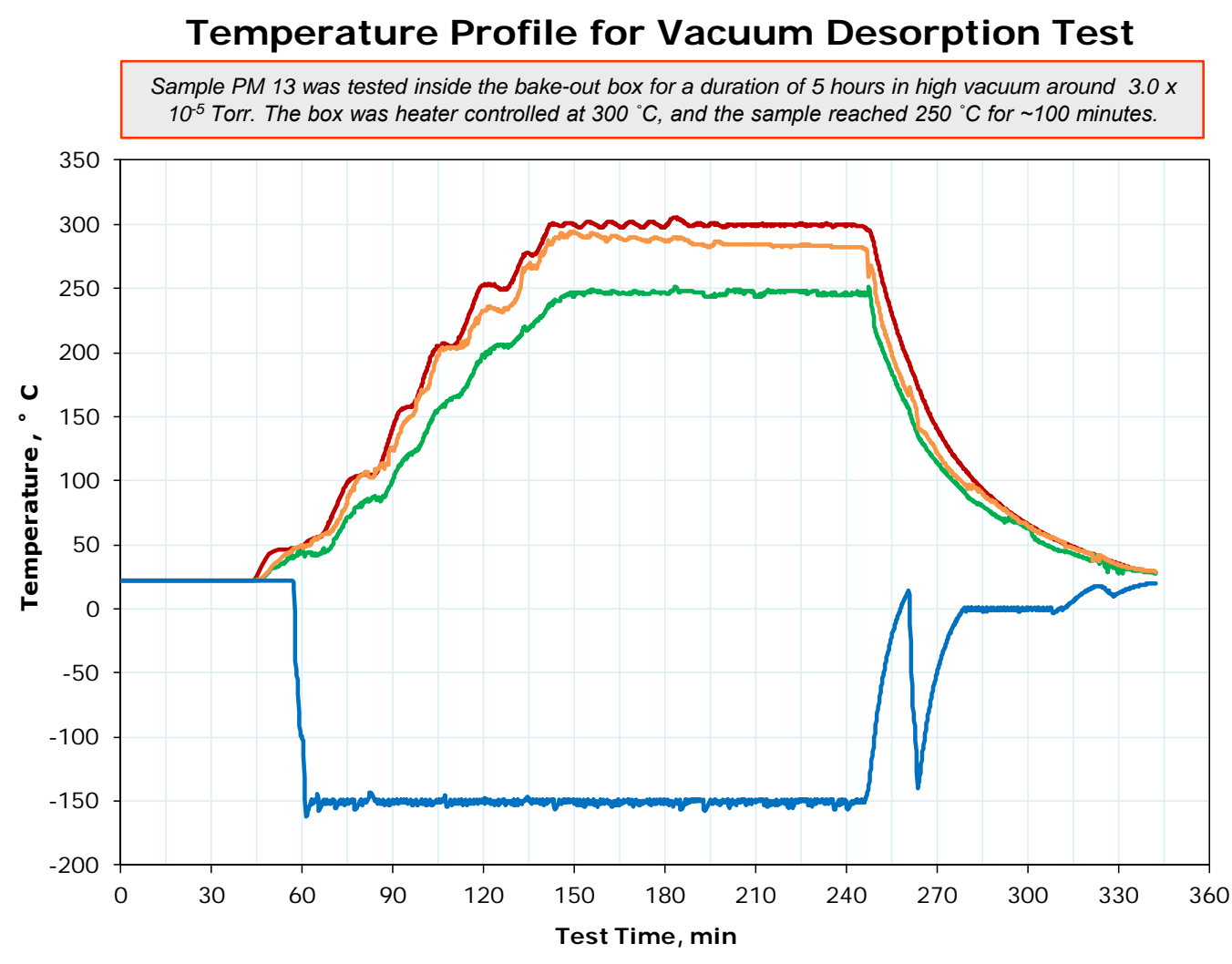

—Box - Side D (with Heater Control) Box - Side B (without Heater Control)
—MAC Plenum Sample (PM 13)

—LN2 Cold Plate

\begin{tabular}{|c|c|}
\hline Rinse & Solvent \\
\hline First & Isopropyl Alcohol \\
\hline
\end{tabular}

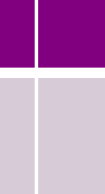

NVR ( mg)
$3.58 \pm 0.04$

\begin{tabular}{l|l|l|l|l} 
Second & Chloroform & $19.78 \pm 0.04$ & $\bullet \quad$ Hydrocarbons (97\%)
\end{tabular}




\section{Chemical Analysis}

- Results demonstrate that chloroform removed over 5.5 times the amount removed from the initial rinse with IPA

- This suggests that IPA does not sufficiently remove the cold plate contaminants that were collected from the sample bake-out at $250{ }^{\circ} \mathrm{C}$

- IPA rinse results show DC-704 diffusion pump oil as the most prevalent NVR species

- This suggests that most of the DC-704 from the cold plate was removed from the initial rinse

- Chemical species found during the chamber background and from the solvent itself were subtracted from the results shown below:

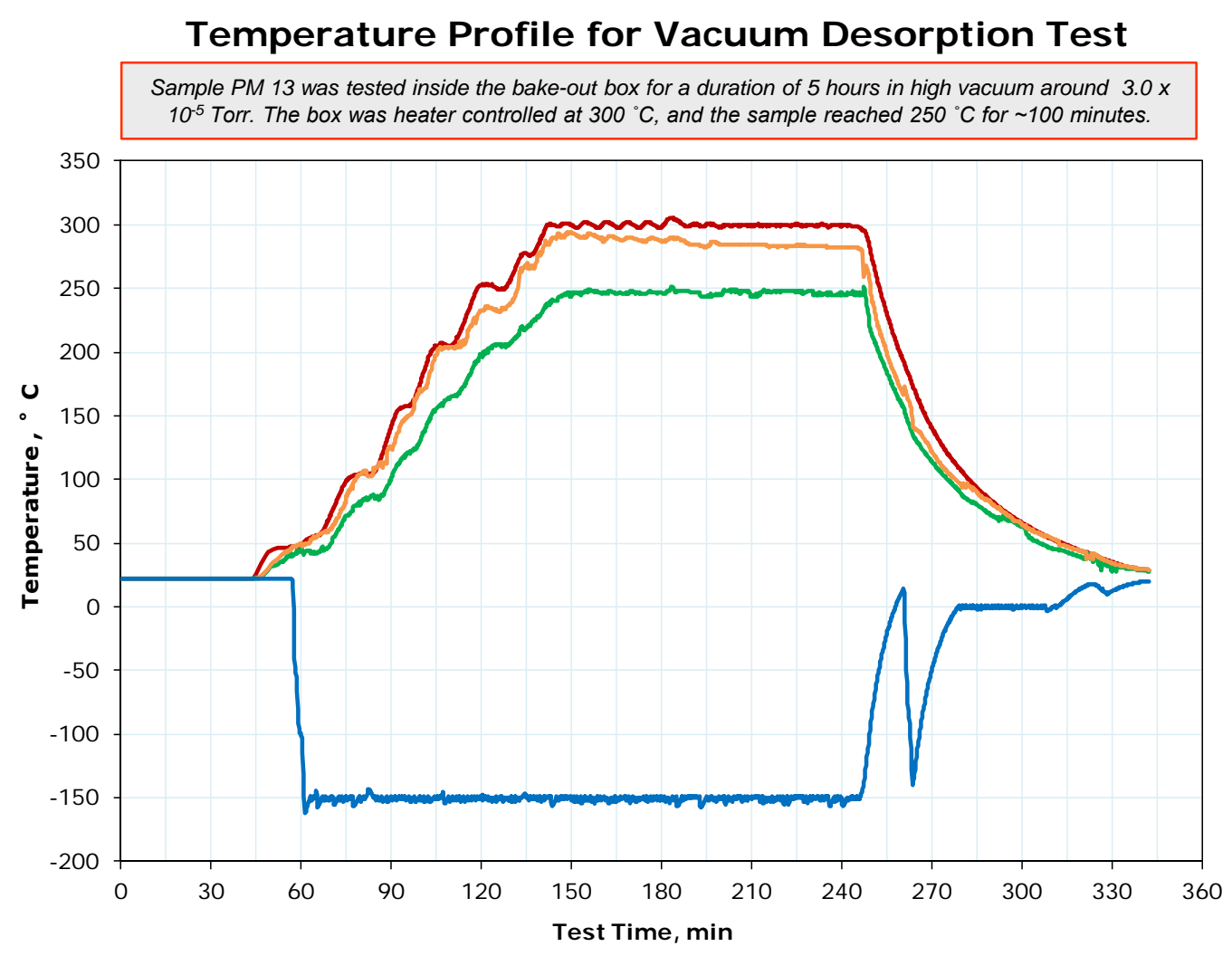

-Box - Side D (with Heater Control)

-Box - Side B (without Heater Control)
—MAC Plenum Sample (PM 13)

—LN2 Cold Plate

\begin{tabular}{|c|c|c|c|}
\hline Rinse & Solvent & NVR (mg) & GC/ MS Analysis \\
\hline First & Isopropyl Alcohol & $3.58 \pm 0.04$ & $\begin{array}{l}\text { DC-704 diffusion pump oil (80\%) } \\
\text { Hydrocarbons }(20 \%)\end{array}$ \\
\hline Second & Chloroform & $19.78 \pm 0.04$ & $\bullet \begin{array}{l}\text { Hydrocarbons }(97 \%) \\
\text { Other }(3 \%)\end{array}$ \\
\hline
\end{tabular}




\section{Chemical Analysis}

\section{Sample Solvent Rinse Method}

- Involves directly rinsing the MAC surface with a solvent

- Destructive test that damages the coating surface

- Qualitatively provides a general approximation of the chemical species that were bound to the surface of the coating and can be dissolved using the selected solvent

- Does not remove all the contaminants that are entrapped on the porous structure of MAC

- Does not provide a complete representation to quantitatively assess the exact amount and types of contaminants that were collected on MAC

- Samples from each OGSE test were rinsed with chloroform

- 4 OGSE- 1 and 4 OGSE-2 barn door panels (Total: 8 samples)

- 4 OGSE- 1 and 4 OGSE-2 plenum samples (Total: 8 samples)

- Similar to the vacuum desorption method:

- Rinsates from the samples were collected and allowed to evaporate to dryness in separate pre-weighed dishes. Remaining NVR was weighed and analyzed using FTIR and pyrolysis-GC/MS

\section{SAMPLE SOLVENT RI NSE PROCEDURE:}

Rinsing the textured coating surface with solvent produced fine particles that were dispersed in the rinsates. Consequently, collected NVR was placed in a micro-vial inside a liner, which was heated in the GC inlet at a high rate of $30{ }^{\circ} \mathrm{C} / \mathrm{sec}$ to a high temperature of $600{ }^{\circ} \mathrm{C}$ for pyrolysis. The volatile and semi-volatile compounds that evolved were then introduced to the GC column interface with the MS for a typical GC/MS run. The nonvolatile compounds remain in the micro-vial to avoid inlet contamination. 


\section{Chemical Analysis}

- NVR results of a single rinse of chloroform on MAC samples from the JWST OGSE tests in Chamber A

- Barn Door Panels: On average, NVR/area increased by a factor of 2 on the second set of panels

\begin{tabular}{|c|c|c|c|c|}
\hline \multirow[t]{2}{*}{ Sample Location/ Type } & \multicolumn{2}{|c|}{$\begin{array}{c}\text { OGSE-1 } \\
\text { Installation Date: May } 2015 \\
\text { Sample Size: } 6 \text { in by } 11 \text { in }\end{array}$} & \multicolumn{2}{|c|}{$\begin{array}{c}\text { OGSE-2 } \\
\text { Installation Date: September } 2015 \\
\text { Sample Size: } 6 \text { in by } 12 \text { in }\end{array}$} \\
\hline & Sample I D & $\begin{array}{l}\text { NVR/ Area } \\
\left(\mu \mathrm{g} / \mathrm{cm}^{2}\right)\end{array}$ & Sample I D & $\begin{array}{l}\text { NVR/ Area } \\
\left(\mu \mathrm{g} / \mathrm{cm}^{2}\right)\end{array}$ \\
\hline \multirow{3}{*}{ MAC Barn Door Panels } & BD 42 & $13.48 \pm 0.09$ & BB 20 & $31.11 \pm 0.09$ \\
\hline & BD 41 & $15.62 \pm 0.09$ & BW 03 & $13.56 \pm 0.09$ \\
\hline & BD 19 & $6.46 \pm 0.09$ & BB 06 & $26.18 \pm 0.09$ \\
\hline Average & \multicolumn{2}{|c|}{$\sim 12 \mu \mathrm{g} / \mathrm{cm}^{2}$} & \multicolumn{2}{|c|}{$\sim 24 \mu \mathrm{g} / \mathrm{cm}^{2}$} \\
\hline
\end{tabular}

- Plenum Samples: On average, NVR/area slightly decreased by about $12 \%$ for the second set of samples

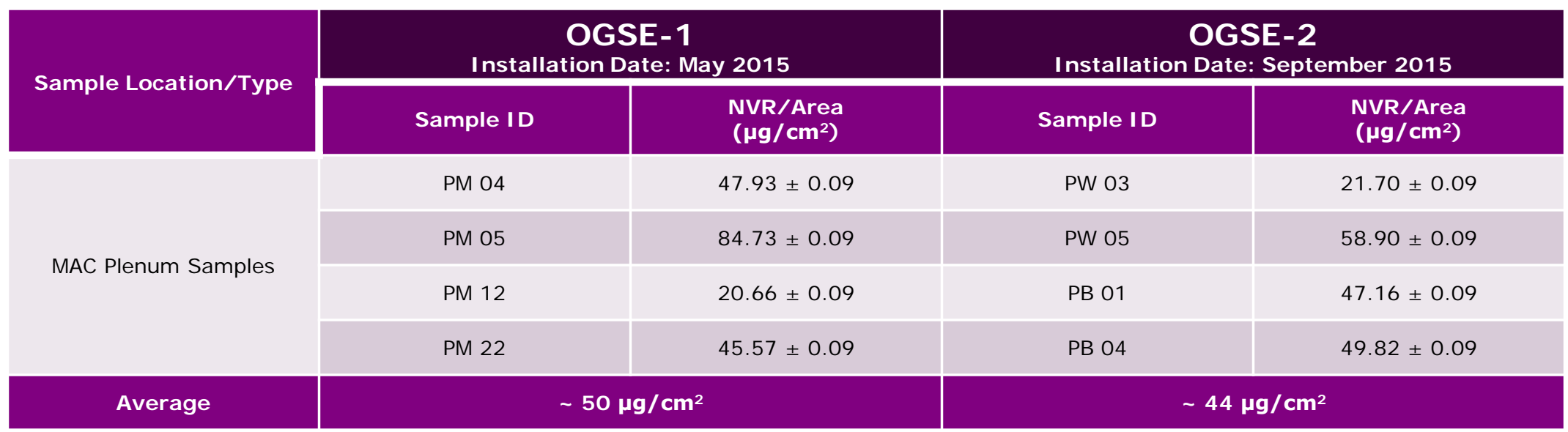




\section{Chemical Analysis}

- One MAC barn door panel (Sample BD 42) from OGSE- 1 was rinsed three times to determine how much additional NVR will be removed with multiple rinses of chloroform

- Results confirm that using this method does not fully remove the chemically adsorbed contaminants

- Two consecutive rinses remove the same amount of contaminant each time

- A third rinse showed a $64 \%$ reduction in NVR than the first two rinses

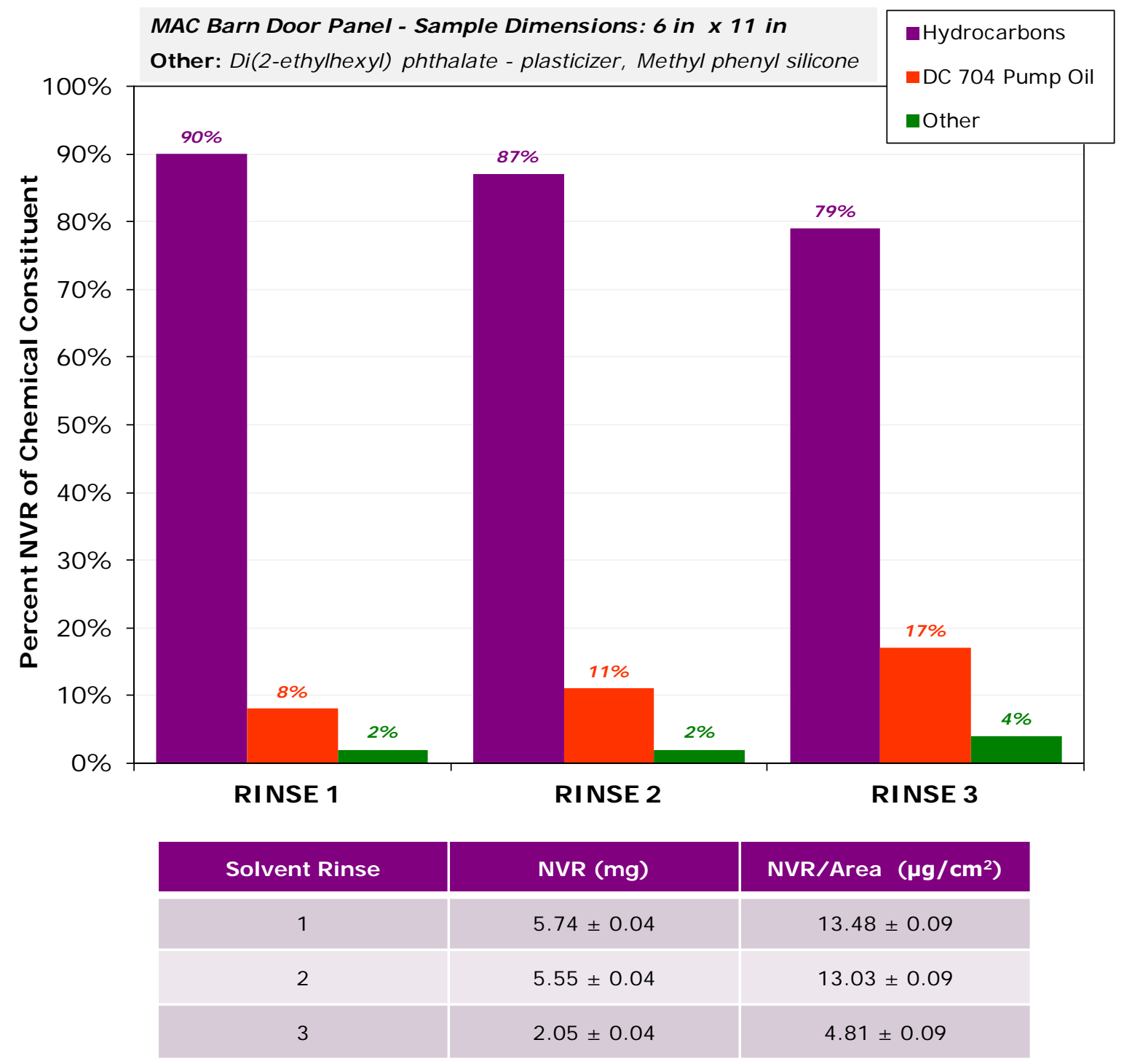




\section{Chemical Analysis}

- Regardless, the significance of this method is to qualitatively determine the types and relative amounts of chemical species that were detected from a solvent rinse of the coating surface

- Each consecutive rinse displays the same chemical species:

- Hydrocarbons (most prominent)

- DC-704

- With each repeated rinse, there is a:

- Gradual reduction of hydro carbons from $90 \%$ to $79 \%$

- Gradual increase of DC-704 present from $8 \%$ to $17 \%$

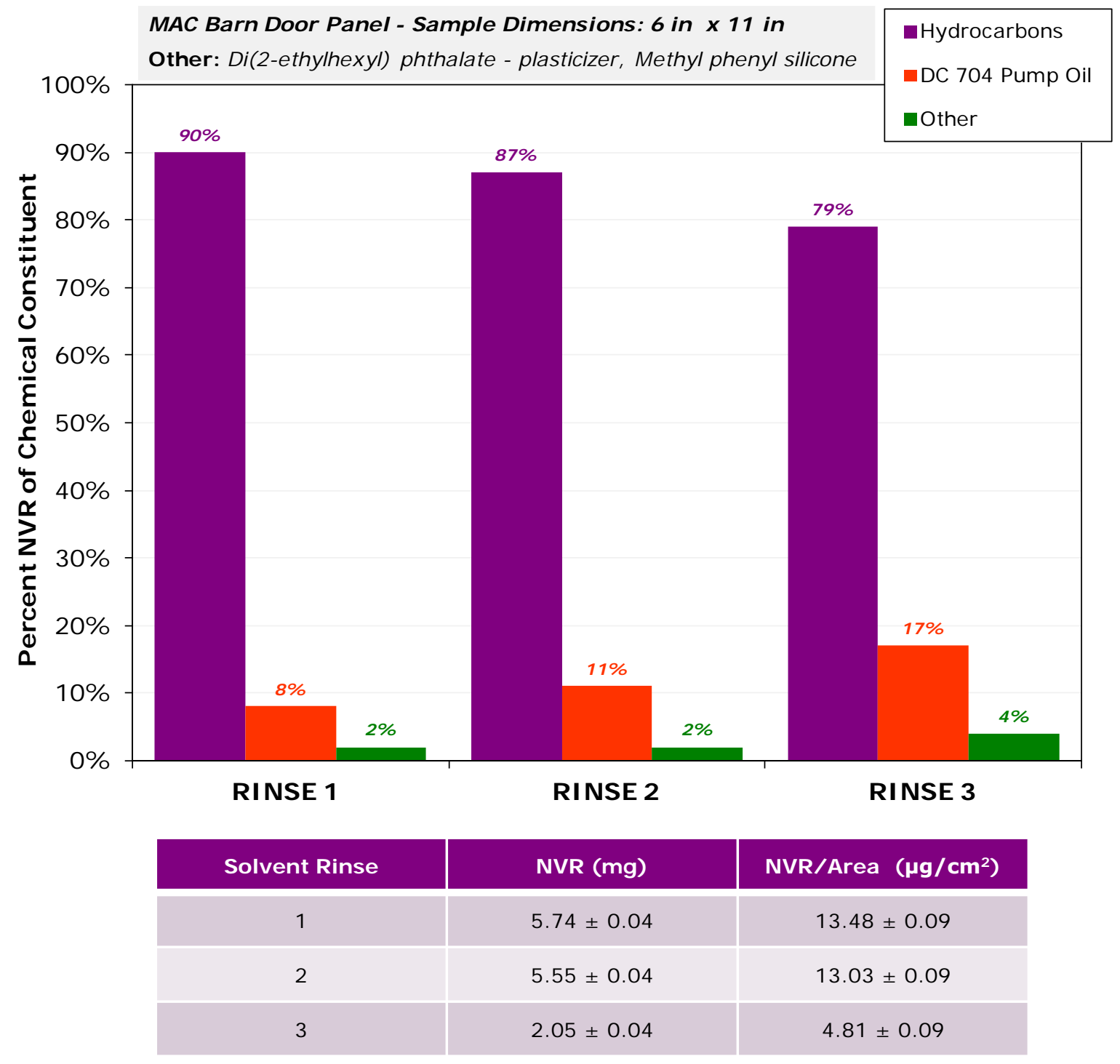




\section{Chemical Analysis}

Single Solvent Rinse Analysis Results from the OGSE-1 Test in May 2015

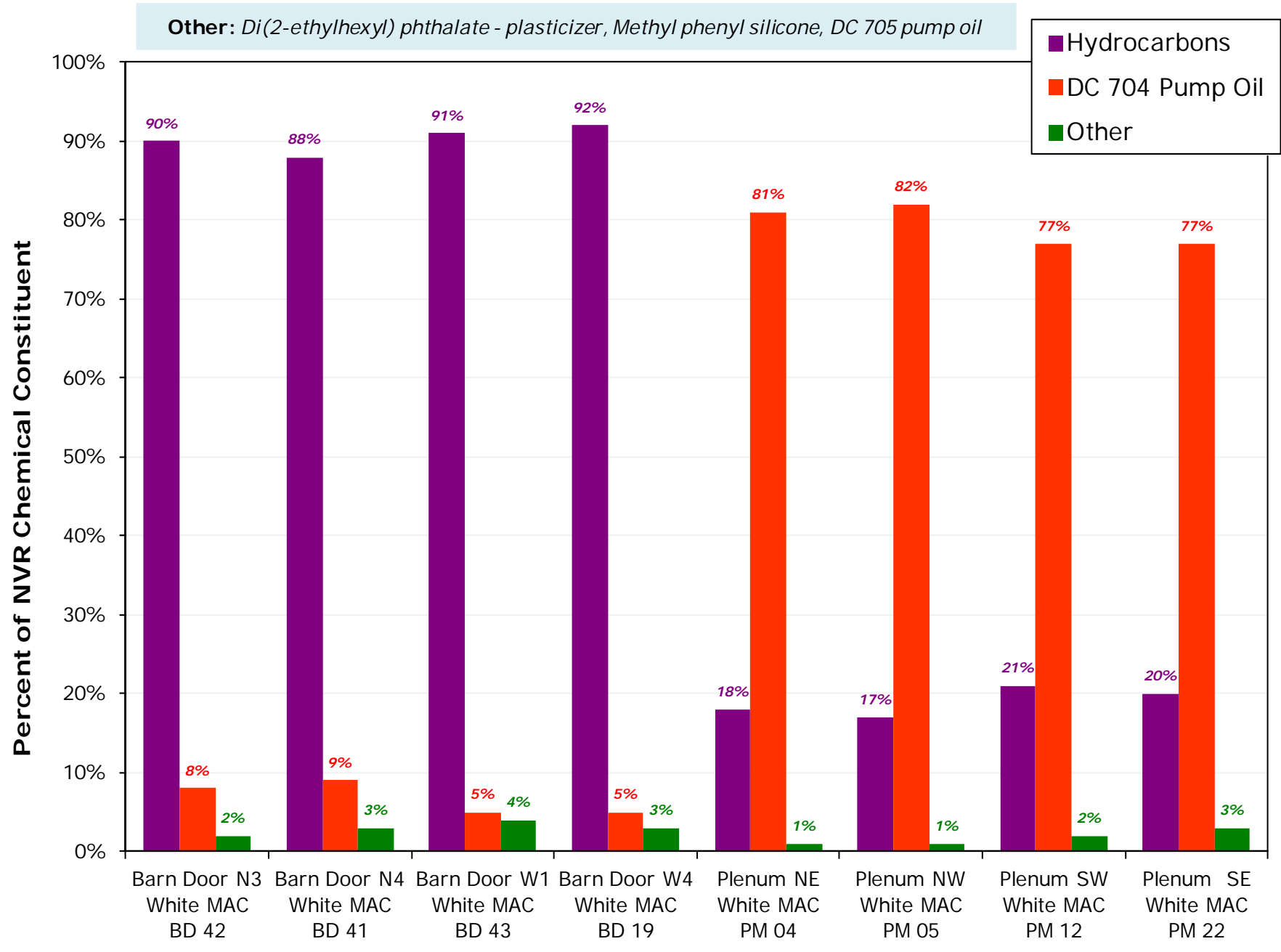

Sample Location, Type of MAC, and Sample I D Number

\section{MAC BARN} DOOR PANELS

High levels of hydrocarbons between $88-92 \%$

\section{Low levels of} DC-704 between $5-9 \%$

As expected, results show migration of DC-704 to the main level of Chamber A near the helium shroud and barn door

\section{MAC PLENUM SAMPLES}

High levels of DC-704 between $77-82 \%$

Low levels of hydrocarbons between $17-20 \%$

This is predictable considering that the plenum is the source of the silicone contamination 


\section{Chemical Analysis}

Single Solvent Rinse Analysis Results from the OGSE-2 Test in September 2015

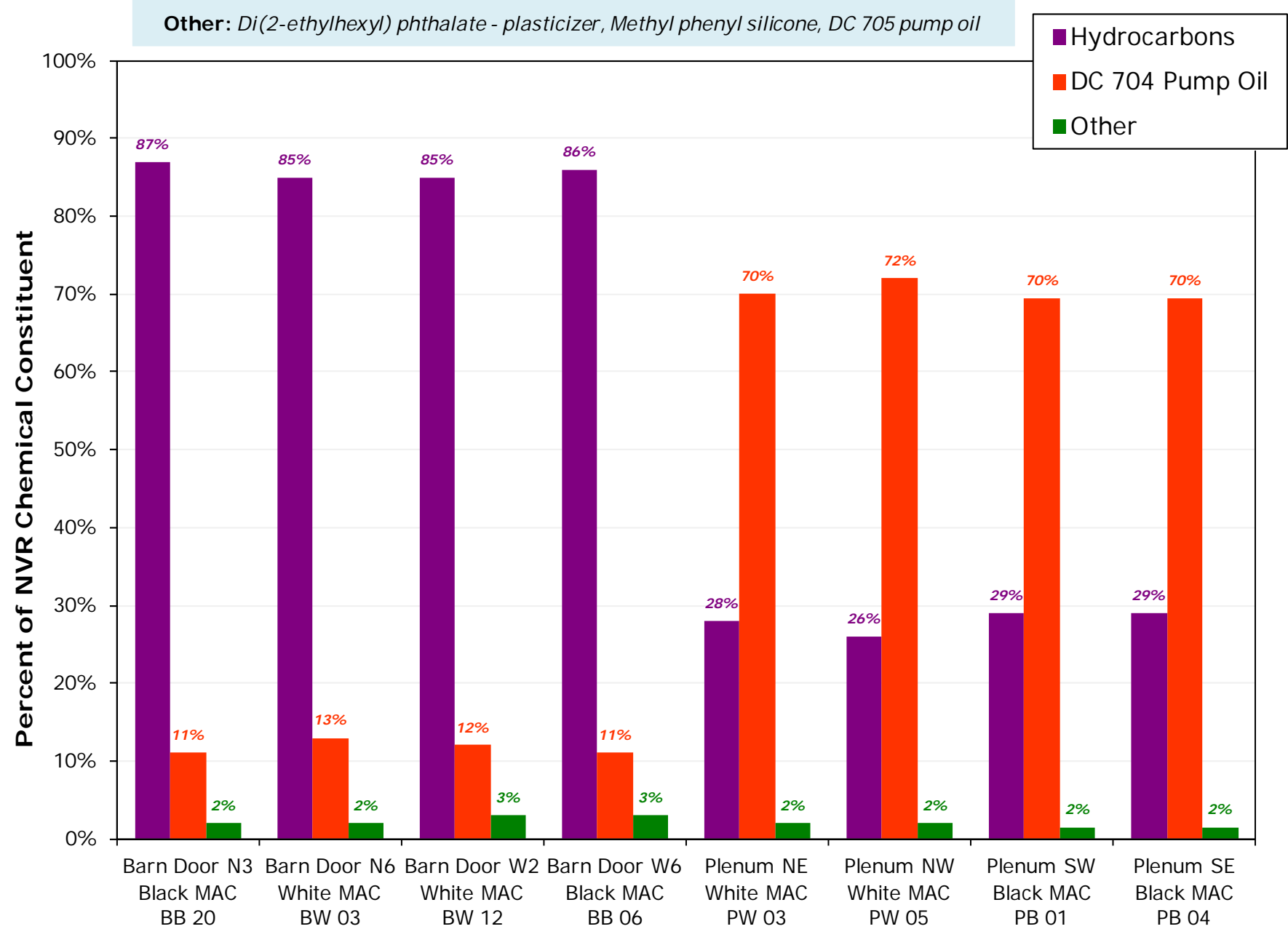

Sample Location, Type of MAC, and Sample ID Number
- Same trends were observed for the MAC samples from the OGSE-2 test

- Main contaminant adsorbed by the barn door panels were hydrocarbons

- Main contaminant adsorbed by the plenum samples were DC-704

- Reduction of 11-12 \% of DC704 adsorbed for OGSE-2 plenum samples compared to OGSE-1 plenum samples

- Relative amounts of hydrocarbons adsorbed on barn door panels were slightly lower, ranging between $85-87 \%$ for OGSE- 2 test 


\section{Chemical Analysis}

FTI R Spectra Comparison for MAC Plenum Sample 14

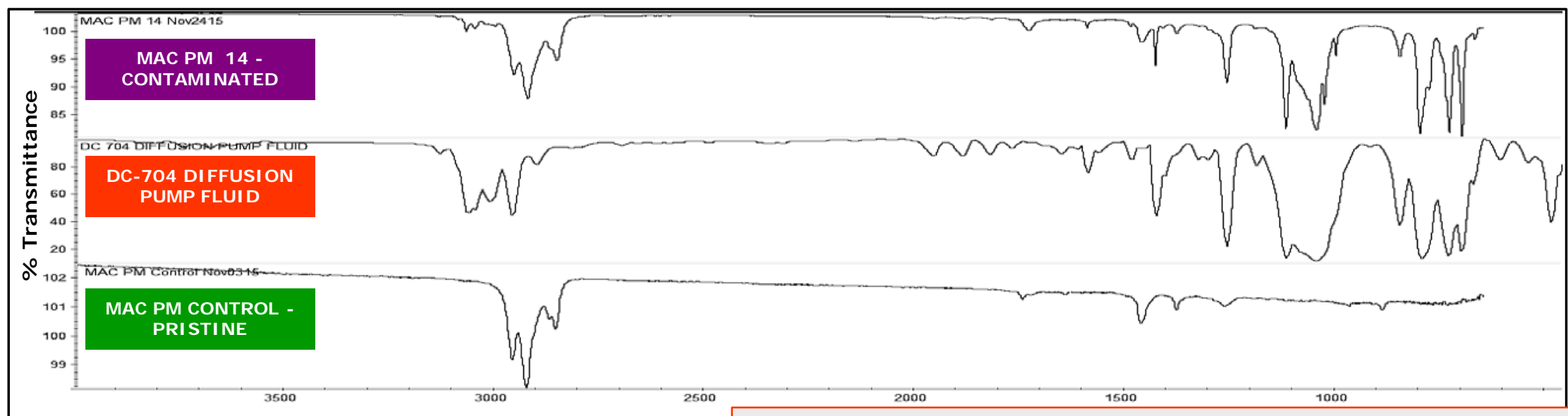

The spectrum illustrates that the contaminated plenum sample is a better match to DC-704 when compared to the contaminated barn door panel spectrum, particularly in the 500 to $2000 \mathrm{~cm}^{-1}$ wavelength range

\section{FTI R Spectra Comparison for MAC Barn Door Panel 41}

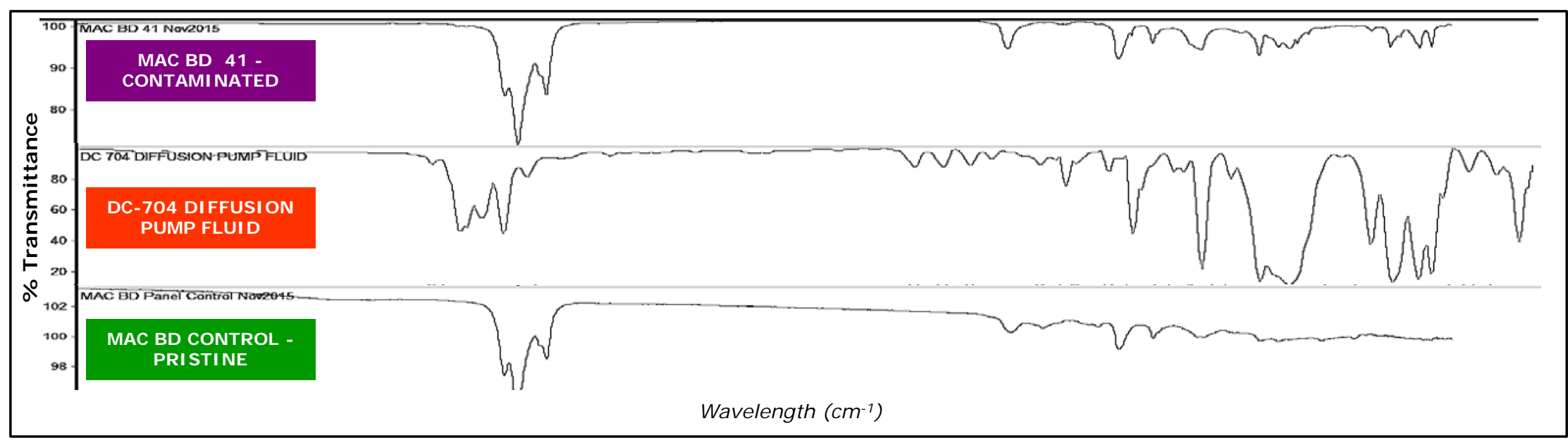




\section{Closing Remarks}

\section{Mitigator and I ndicator}

- MAC can serve not only as a contaminant risk mitigator, but also as a contaminant indicator by identifying the molecular contamination risks in the chamber that may not be collected on post vacuum witness foils

- For instance, molecular species that strike the coating surface are captured and less likely to be released during warm-up to ambient conditions

- Results from laboratory testing and chemical analysis methods have proven that MAC will continue to:

- Collect outgassed silicone based diffusion pump oil

- Reduce the risk of molecular contamination from the chamber to test equipment

\section{Coating Particulation}

- Particulation related anomalies from MAC were not observed during post test chamber inspections 


\section{Conclusions}

- Future Plans

- Acknowledgements

- References

- Contact I nformation 


\section{Future Plans}

- Continued use of MAC is planned for upcoming tests due to the successful application during the JWST OGSE tests in Chamber A

- Currently planned for use for the JWST Thermal Pathfinder Test

- Tentatively scheduled for Fall 2016

- Future work include:

- Fine tuning the chemical analysis methods for determining the amount of contaminants adsorbed onto the coating

- For example:

- Exploring different solvents for rinsing

- Improving vacuum desorption tests for greater test efficiency

- Investigating other tear resistant substrates

- Performing more analysis on future samples

- Continuing to expand upon the benefits of using MAC for vacuum chamber applications 


\section{Acknowledgements}

- A summary of the authors of this SPIE paper, their affiliations, and support roles for this JWST/MAC effort are described below:

\section{Nithin S. Abraham}

- NASA Goddard Space Flight Center, Code 546

- MAC Research and Development Lead Coatings Engineer

\section{Mark M. Hasegawa}

- NASA Goddard Space Flight Center, Code 546

- Thermal Coatings Application and Development Group Lead

\section{Eve M. Wooldridge}

- NASA Goddard Space Flight Center, Code 546

- JWST Project Support Contamination Engineer Lead

\section{Kelly A. Henderson-Nelson}

- Stinger Ghaffarian Technologies, I nc., Code 546

- JWST Project Support Contamination Engineer 


\section{Acknowledgements}

- The authors of this paper would like to thank the J WST Program Office at NASA GSFC for funding this coatings application and testing effort. The authors would also like to acknowledge some talented individuals who have contributed to this effort.

\section{A special thanks to:}

\begin{tabular}{|c|c|c|c|}
\hline NAME & AFFI LI ATI ON & NASA GSFC CODE & DESCRI PTI ON \\
\hline J oseph Ward & SGT, Inc. & Code 546 & Chamber A Contamination Support \\
\hline Niko Stergiou & SGT, Inc. & Code 546 & Chamber A Contamination Support \\
\hline Jason Durner & SGT, Inc. & Code 546 & Chamber A Contamination Support \\
\hline John Petro & NASA GSFC & Code 546 & Coatings Application Support \\
\hline Alfred Wong & SGT, Inc. & Code 546 & Coatings Application Support \\
\hline Grace Miller & SGT, Inc. & Code 546 & Coatings Application Support \\
\hline Kenneth O'Connor & SGT, Inc. & Code 546 & $\begin{array}{l}\text { Sample Fabrication } \\
\text { Coatings Testing \& Measurement Support }\end{array}$ \\
\hline Alexson Harris-Kirksey & Telophase & Code 504 & Coatings Testing \& Measurement Support \\
\hline Griffin J ayne & SGT, Inc. & Code 546 & Coatings Testing \& Measurement Support \\
\hline George Meadows & SGT, Inc. & Code 546 & Coatings Testing \& Measurement Support \\
\hline Doris J allice & NASA GSFC & Code 541 & Chemical Analysis Support \\
\hline Paul Pless & SGT, Inc. & Code 541 & Chemical Analysis Support \\
\hline Jeremy Knipple & SGT, Inc. & Code 541 & Chemical Analysis Support \\
\hline
\end{tabular}




\section{References}

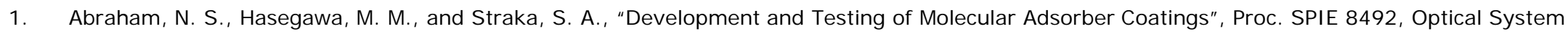
Contamination: Effects, Measurements, and Control 2012, 849203 (October 2012)

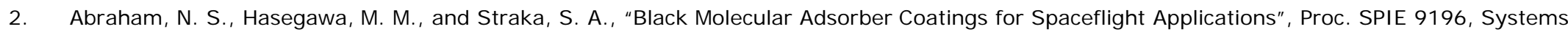
Contamination: Prediction, Measurement, and Control 2014, 91960F (September 2014)

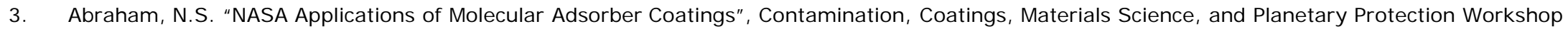
(July 2015)

4. Abraham, N.S. "NASA Applications of Molecular Adsorber Coatings", Thermal and Fluids Analysis Workshop (August 2015)

5. Jousten, K. Handbook of Vacuum Technology. Weinheim: Wiley-Blackwell, (2008)

6. Hablanian, M. H. High-Vacuum Technology: A Practical Guide, 2nd ed. Revised and Expanded, New York: M. Dekker, (1997)

7. O'Hanlon, J. F., A User's Guide to Vacuum Technology, New York: Wiley, (1980)

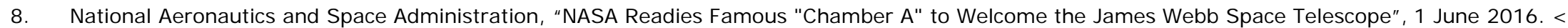
http://www.nasa.gov/mission_pages/webb/news/chamber-a.html>

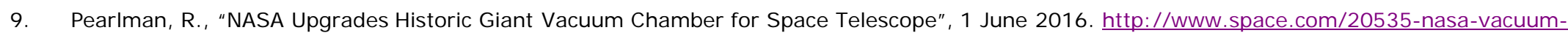
chamber-space-telescope.html

10. National Aeronautics and Space Administration, "Chamber A", 1 J une 2016.

http://www.nasa.gov/centers/johnson/engineering/integrated_environments/altitude_environmental/chamber_A/

11. National Aeronautics and Space Administration, “James Webb Space Telescope”, 1 June 2016. <http://www.jwst.nasa.gov/>

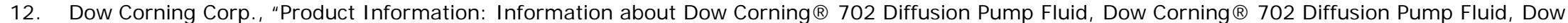
Corning ${ }^{\circledR} 702$ Diffusion Pump Fluid", Form No. 10-838-98 (1998)

13. Neptco Inc., “NepTape ${ }^{\circledR} 1026$ Data Sheet: Shielding Tape - Standard Foil/Film/Foil Laminates NepTape ${ }^{\circledR}$ 1026” (August 2000)

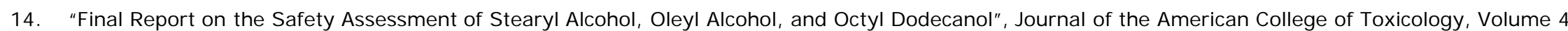
- Number 5, Mary Ann Liebert, Inc., Publishers, (1985)

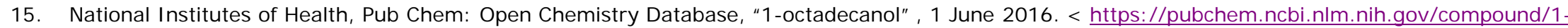
octadecanol\#section $=$ Top $>$

16. National Institutes of Health, Pub Chem: Open Chemistry Database, "Tetraphenyl-1,3,3,5-tetramethyltrisiloxane" , 1 June 2016. < https://pubchem.ncbi.nlm.nih.gov/compound/19882\#section=Top>

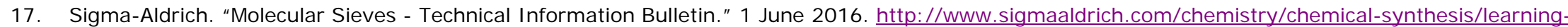
center/technical-bulletins/al-1430/molecular-sieves.html

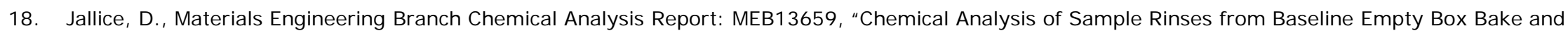
Bake of MAC Foil from JWST JSC OGSE-1 Plenum" (February 2016)

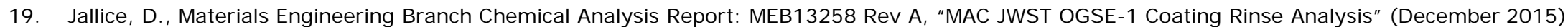

20. Jallice, D., Materials Engineering Branch Chemical Analysis Report: MEB13526, "MAC JWST OGSE-2 Coating Rinse Analysis" (January 2016) 


\section{Contact I nformation}

Nithin S. Abraham

Thermal Coatings Engineer

NASA Goddard Space Flight Center, Code 546

Contamination and Coatings Engineering Branch

E-mail: nithin.s.abraham@nasa.gov

Phone: (301) 614-7070 